\title{
Molecular Line Parameters for the "MASTER" (Millimeter Wave Acquisitions for Stratosphere/Troposphere Exchange Research) Database
}

\author{
A. PERRIN ${ }^{1}$, C. PUZZARINI ${ }^{2}$, J.-M. COLMONT ${ }^{3}$, C. VERDES ${ }^{4}$, \\ G. WLODARCZAK ${ }^{3}$, G. CAZZOLI ${ }^{2}$, S. BUEHLER ${ }^{4}$, J.-M. FLAUD ${ }^{1}$ \\ and J. DEMAISON ${ }^{3}$
}

${ }^{1}$ Laboratoire Interuniversitaire des Systèmes Atmosphèriques (LISA), UMR CNRS 7583, Université Paris 12 - Val-de-Marne, UFR des Sciences et Technologie, Bât. P1, 61, avenue du Général de Gaulle, 94010 Créteil Cedex, France, e-mail: Perrin@lisa.univ-paris12.fr

${ }^{2}$ LMSB, Dipartimento di Chimica "G. Ciamician”, Università di Bologna, Via F. Selmi 2, 40126 Bologna, Italy

${ }^{3}$ Laboratoire de Physique des Lasers, Atomes et Molécules (PhLAM), UMR CNRS 8523, Université de Lille 1, Bat P5, F-59655 Villeneuve d'Ascq, France

${ }^{4}$ Institute of Environmental Physics (ife), University of Bremen/FB 1, P.O. Box 330440, 28334

Bremen, Germany

(Received: 15 June 2004; accepted: 2 December 2004)

\begin{abstract}
In order to investigate the upper troposphere/lower stratosphere (UTLS) region of the earth's atmosphere, ESA/ESTEC (European space agency) is considering the opportunity to develop the spaceborne limb sounding millimeter sensor "MASTER" (millimeter wave acquisitions for stratosphere/troposphere exchange research). This instrument is part of the "atmospheric composition explorer for chemistry and climate interactions" (ACECHEM) project. In addition, ESA/ESTEC is developing the "MARSCHALS" (millimeter-wave airborne receiver for spectroscopic characterization of atmospheric limb sounding) airborne instrument which will demonstrate the feasibility of MASTER. The present paper describes the line-by-line database which was generated in order to meet at best the needs of the MASTER (or MARSCHALS) instrument. The linelist involves line positions, line intensities, line broadening and line shift parameters in the 294-305, 316-325, 342348, 497-506 and 624-626 GHz spectral microwindows. This database was first generated for the target molecules for MASTER $\left(\mathrm{H}_{2} \mathrm{O}, \mathrm{O}_{3}, \mathrm{~N}_{2} \mathrm{O}, \mathrm{CO}, \mathrm{O}_{2}, \mathrm{HNO}_{3}, \mathrm{HCl}, \mathrm{ClO}, \mathrm{CH}_{3} \mathrm{Cl}, \mathrm{BrO}\right)$. In addition, ten additional molecules $\left(\mathrm{SO}_{2}, \mathrm{NO}_{2}, \mathrm{OCS}, \mathrm{H}_{2} \mathrm{CO}, \mathrm{HOCl}, \mathrm{HCN}, \mathrm{H}_{2} \mathrm{O}_{2}, \mathrm{COF}_{2}, \mathrm{HO}_{2}\right.$ and $\mathrm{HOBr}$ ) had also to be considered in the database as "possible interfering species" for the retrieval of the target molecules of MASTER. The line parameters were derived, depending on their estimated accuracy, (i) from a combination of spectral parameters included in the JPL and HITRAN catalogs (ii) from data taken into the literature or (iii) using data obtained through experimental measurements (and/or) calculations performed during the present study.
\end{abstract}

Key words: broadening coefficients, millimeter and submillimeter spectral domains, line intensities, line positions, spectroscopic database 


\section{Introduction}

Millimeter and sub-millimeter wave techniques have been extensively used or are under development since many years in order to perform remote observations of the Earth's middle atmosphere. These studies involve ground-based microwave radiometers (de La Noë et al., 1983; Nedoluha et al., 1995; de La Noë et al., 1998; Raffalski et al., 1998), airborne (Titz et al., 1995; De Valk et al., 1997) and balloon-borne (Pardo et al., 2000) sensors.

Remote sensing of the Earth's atmosphere from satellite platforms is essential for the understanding of stratospheric ozone chemistry and climatology because the spatial concentration of numerous trace gases can be monitored simultaneously on a global scale. The upper troposphere/lower stratosphere (UTLS) region is a major focus of interest for atmospheric research due to the importance of this region to climate radiative forcing, stratosphere/troposphere exchanges and tropospheric chemistry.

Although sensors working in the infrared (IR) or visible ultra violet (VISUV) spectral regions like the Michelson interferometer for passive atmospheric souding (MIPAS) or the scanning imaging absorption spectrometer for atmospheric chartography (SCIAMACHY) on the environmental satellite (ENVISAT http://envisat.esa.int/) have potential to sound this region of the atmosphere, it is anticipated that the attributes of millimeter wave limb sounding would be especially well suited to the task since the quality of the retrievals is less affected by clouds and aerosols than in the infrared, visible or ultraviolet wavelengths. On the other hand, continuum emission from water and dry air limits this advantage. At present stratospheric limb sounding has already been demonstrated successfully by instruments like the microwave limb sounder (MLS) on the upper atmosphere research satellite (UARS) (Lahoz et al., 1994; Eluszkiekicz et al., 1996 Livesey et al., 2003 and references therein) and more recently by the sub millimeter radiometer (SMR) on board the Odin satellite since February 2001 (Murtagh et al., 2002; Eriksson et al., 2002; Baron et al., 2002; Merino et al., 2002; Pardo et al., 2002; Ridal et al., 2002; Urban et al., 2004). Also the NASA's Earth observation system microwave limb sounder (EOS-MLS) was launched in 2004. In addition, there exist new projects, like the heterodyne sub-millimeter receiver JEM/SMILES (superconducting sub-millimeter wave limb emission sounder) which would operate on the Japanese experimental module (JEM) on the International space station (ISS) (http://smiles.tksc.nasda.go.jp/).

The European space agency (ESA/ESTEC) investigates the possibility to develop the spaceborne limb sounding millimeter sensor "MASTER" (millimeter wave acquisitions for stratosphere/troposphere exchange research). This instrument is part of the "atmospheric composition explorer for chemistry and climate interactions" (ACECHEM) project. The mission objectives of MASTER are to perform limb measurements of spatially variable gases (see Table I) in the 294$626 \mathrm{GHz}$ spectral region in appropriate altitude ranges and with adequate vertical 
Table I. Primary instrument requirements for MASTER

\begin{tabular}{lllllll}
\hline Primary targets & $\begin{array}{l}\text { Height } \\
\text { domain }\end{array}$ & $\begin{array}{l}\text { Spectral } \\
\text { coverage } \\
(\mathrm{GHz})\end{array}$ & $\begin{array}{l}\text { Spectral } \\
\text { resolution } \\
(\mathrm{MHz})\end{array}$ & $\begin{array}{l}\text { NEBT/ } \\
\text { accuracy } \\
(\mathrm{K})\end{array}$ & $\begin{array}{l}\text { Vertical } \\
\text { HPBW } \\
(\mathrm{Km})\end{array}$ \\
\hline $\mathrm{O}_{3}, \mathrm{~N}_{2} \mathrm{O}, \mathrm{O}_{2}$ (pointing) $\mathrm{HNO}_{3}$ & UT/LS & B & $294.0-305.5$ & 50 & $1.2 / 1.0$ & 2.3 \\
$\mathrm{H}_{2} \mathrm{O}, \mathrm{O}_{3}$ & UT/LS & $\mathrm{C}$ & $316.5-325.5$ & 50 & $1.3 / 1.0$ & 2.3 \\
$\mathrm{CO}, \mathrm{HNO}_{3}, \mathrm{BrO}$ & $\mathrm{UT} / \mathrm{LS}$ & $\mathrm{D}$ & $342.25-348.75$ & 50 & $0.5 / 1.0$ & 2.3 \\
$\mathrm{ClO}, \mathrm{O}_{3}, \mathrm{~N}_{2} \mathrm{O}, \mathrm{BrO}, \mathrm{H}_{2} \mathrm{O}, \mathrm{CH}_{3} \mathrm{Cl}$ & $\mathrm{LS}$ & $\mathrm{E}$ & $497.0-506.0$ & 50 & $0.6 / 1.0$ & 1.6 \\
$\mathrm{HCl}, \mathrm{O}_{3}$ & LS & F & $624.0-626.5$ & 50 & $2.0 / 1.0$ & 1.6 \\
\hline
\end{tabular}

Note. $\mathrm{LS}=$ lower stratosphere, $\mathrm{UT}=$ upper troposphere, $\mathrm{NEBT}=$ noise equivalent brightness temperature, HPBW = antenna half-power beam width.

resolution. In parallel to MASTER studies, ESA has defined a program to develop and deploy MARSCHALS (millimeter-wave airborne receiver for spectroscopic characterisation of atmospheric limb sounding), an airborne simulator for the proposed spaceborne instrument MASTER. The primary objective of MARSCHALS is to demonstrate the feasibility of limb sounding at millimeter and sub-millimeter wavelength (microwindows B, C and D of Table I). The most innovative of MASTER's capabilities, which MARSCHALS should seek to simulate as closely as possible, is that of UT limb sounding.

In order to retrieve the atmospheric parameters (pressure, temperature, concentration profiles, ...) with the best possible accuracy, it is essential to have spectral parameters of high quality. Therefore, compilations of parameters which include for each transition the line position, the line intensity, the lower state energy, the vibrational and rotational assignments, various line shape parameters (depending on the databases), together with some error estimates and relevant literature data are constantly updated.

The main compilations in the microwave and millimeter wave (MW/MMW) domain are the HITRAN (high-resolution transmission) (Rothman et al., 1983, 1992, 1998, 2003) database and the JPL (Jet Propulsion Laboratory) (Poynter and Pickett, 1985; Pickett et al., 1998) catalog.

\subsection{THE HITRAN DATABASE}

The HITRAN database (Rothman et al., 1983, 1992, 1998, 2003) is focused mainly on atmospheric applications. The line-by-line subsection which covers the 0 $20,000 \mathrm{~cm}^{-1}$ spectral range includes for each line the position, the intensity (at 296 K) for a sample with "natural" isotopic concentrations (de Bievre et al., 1984), the lower state energy, the air- and self-pressure-broadening coefficients (Half Width at Half Maximum at $296 \mathrm{~K}$ ), the $n$-temperature dependence of the air-broadening coefficient, the air-pressure shift coefficient, the vibrational and rotational assignments and indices giving errors estimates and relevant literature data. 


\subsection{THE JPL CATALOG}

The JPL catalog (Poynter and Pickett, 1985; Pickett et al., 1998) is devoted to the microwave and millimeter wave (MW/MMW) spectral range and was initially generated for astrophysical applications. This catalog includes line positions and line intensities quoted at $300 \mathrm{~K}$ for a pure isotopic sample for an extended set of molecules involving numerous isotopic species. There are also files with informations about the source of the molecular data, updates and partition functions. Actually as stressed by Pickett et al. (1998) for numerous (but not all) species, the JPL line intensities were generated using a partition function which accounts only for the rotation and nuclear spin (and/or) electron spin contributions $Z_{\text {Spin-Rot }}(T)$ to the "total" partition function $\mathrm{Z}_{\mathrm{Tot}}(\mathrm{T})$. In fact the total partition function $\mathrm{Z}_{\mathrm{Tot}}(\mathrm{T})$

$$
Z_{\mathrm{Tot}}(T) \approx Z_{\text {Spin-Rot }}(T) Z_{\mathrm{Vib}}(T)
$$

includes also a "vibrational" contribution $Z_{\mathrm{vib}}(T)$ which, assuming the harmonic approximation takes the general form:

$$
Z_{\mathrm{Vib}}(T)=\prod_{\mathrm{Vib}}\left(1-\exp ^{-E_{\mathrm{Vib}} / \mathrm{kT}}\right)^{-d_{\mathrm{Vib}}}
$$

where the product runs over the different modes of vibration of the molecule with $d_{\mathrm{Vib}}$ as the associated degeneracy.

For that reason, the JPL intensities which are generated at $300 \mathrm{~K}$ are overestimated for a number of species by a factor equal to $Z_{\mathrm{Vib}}(300 \mathrm{~K})$ which is non negligible for molecules with rather low vibrational modes. Therefore, these line intensities have to be corrected before their introduction into databases of atmospheric interest, and this has been done for the databases generated for the ODIN satellite (Eriksson et al., 2002) as well as in the present database. Finally all the line shape parameters (air- and self-broadening parameters and line air-pressure shift) are completely absent in the JPL catalog.

\subsection{DATABASE GENERATED TO A DEDICATED INSTRUMENT}

Apart from these general databases it is worth noticing that some databases were generated for a dedicated instrument. This was the case some years ago for the ATMOS (molecular line parameters for the atmospheric molecule trace spectroscopy) experiment (Brown et al., 1987), for the SAO (Smithsonian Astrophysical Observatory) FIRS-2 balloon borne spectrometer (Chance et al., 1994a), and, more recently, for the MIPAS instrument (Flaud et al., 2003b) which is on board the ENVISAT satellite.

The present paper describes the line-by-line database which has been generated in order to meet the needs of the MASTER (or MARSCHALS) instrument. The parameters (line positions, line intensities, line broadening and pressure shifts) included in this database are provided both for the target molecules for MASTER, 
namely, water $\left(\mathrm{H}_{2} \mathrm{O}\right)$, ozone $\left(\mathrm{O}_{3}\right)$, nitrous oxide $\left(\mathrm{N}_{2} \mathrm{O}\right)$, carbon oxide $(\mathrm{CO})$, oxygen $\left(\mathrm{O}_{2}\right)$, nitric acid $\left(\mathrm{HNO}_{3}\right)$, hydrogen chloride $(\mathrm{HCl})$, chloride oxide $(\mathrm{ClO})$, methyl chloride $\left(\mathrm{CH}_{3} \mathrm{Cl}\right)$, bromide oxide $(\mathrm{BrO})$, see Table I) and for the possible interfering species, namely sulfur dioxide $\left(\mathrm{SO}_{2}\right)$, nitrogen dioxide $\left(\mathrm{NO}_{2}\right)$, carbonyl sulfide (OCS), formaldehyde $\left(\mathrm{H}_{2} \mathrm{CO}\right)$, hypochlorous acid $(\mathrm{HOCl})$, hydrogen cyanide ( $\mathrm{HCN})$, hydrogen peroxide $\left(\mathrm{H}_{2} \mathrm{O}_{2}\right)$, carbonyl fluoride $\left(\mathrm{COF}_{2}\right)$, hydroperoxyl radical $\left(\mathrm{HO}_{2}\right)$ and hypobromous acid $(\mathrm{HOBr})$.

These line parameters were derived, depending on their availability and their estimated accuracy, (i) from a combination of parameters extracted from the JPL (Poynter and Pickett, 1985; Pickett et al., 1998) and HITRAN (Rothman et al., 1998,2003 ) catalogs (ii) from data taken into the literature or (iii) using data obtained through experimental measurements and/or calculations performed during two recent studies (Bauer et al., 1998a; Demaison et al., 2004 and references therein).

Actually, the uncertainties in the knowledge of the spectroscopic parameters can lead to systematic errors during the retrieval of the atmospheric volume mixing ratio (VMR) and temperature profiles. To assess more precisely the parameters for which an improved accuracy is needed, a forward calculation accompanied by a detailed errors analysis with respect to the spectroscopic parameters was performed. These calculations (Verdes et al., 2004, 2005) involve inversions of the atmospheric measurements performed for a realistic MASTER observation scenario using the formalism developed by Rodgers (2000).

As it will be seen in the following, the available line positions parameters are almost always accurate enough for MASTER. For some of the species under study, new line intensity calculations had to be performed. As expected, the air-broadening parameters (the air-broadening coefficients $\gamma_{\text {air }}$ and their $n$ temperature dependences $n_{\text {air }}$ ), existing in the literature are not often accurate enough. The self broadening coefficients $\gamma_{\text {self }}$ are often unknown but, except for water and oxygen, have anyway a negligible effect on the quality of the retrieval analysis. Finally, the air line shifts are still rather sparse, but during the course of this study, it was established that the pressure shifts seem to lead to rather negligible effects for the MASTER retrievals. Therefore, unless explicitly specified, a zero default value was quoted in MASTER for the air pressure shift and the self broadening linewidth. Also the default value " $n=0.7$ " was quoted for the temperature dependence of the air- and self-broadening parameters.

For the parameters for which the impact of the associated errors on the retrievals appear to be important, measurements had to be performed in some cases in Bologna (LMSB), Lille (PhLAM) and Wessling (Deutsches Zentrum für Luft- und Raumfahrt), the results of which are described in extensive reports (Bauer et al., 1998a, Demaison et al., 2004). 


\section{Description of the MASTER Database}

In the MASTER database the line positions are in $\mathrm{MHz}$ and the lower state energies in $\mathrm{cm}^{-1}$. The line intensities $S_{\text {MASTER }}$ are quoted in $\mathrm{cm}^{-1} /\left(\right.$ molecule $\left.\mathrm{cm}^{-2}\right)$ at $T_{\text {Ref }}=296 \mathrm{~K}$ for a pure isotopic sample (contrary to HITRAN). The air pressure-broadening coefficients $\gamma_{\text {air }}$ the self pressure-broadening coefficients $\gamma_{\text {self }}$ and the air pressure-shifts $\delta_{\text {air }}$ are given (in MHz/Torr) for a reference temperature $T_{\text {Ref }}=296 \mathrm{~K}$. However when they were measured these parameters are given at the temperature of the measurements $T_{\text {meas }}$ which is also quoted in the database. Finally, the MASTER database includes also the coefficients $n_{\text {air }}$ and $n_{\text {self }}$ necessary to calculate the temperature dependence for air-broadening and self-broadening coefficients. It is important to underline that the line shape parameters were implemented assuming a Voigt profile for all the lines. Possible deviations from this "classical" line profile may occur (Puzzarini et al., 2002; Rohart et al., 2003) for some specific laboratory conditions. Two possible reasons can be responsible for these deviations: the velocity changing collisions (Dicke, 1953) leading to a Galatry profile (Galatry, 1961) or the speed dependence of the relaxation rates, and both profiles give a better fit to experimental data and lead to broadening coefficients in good agreement. However, in usual atmospheric conditions the collisional line broadening is signicantly stronger, in the millimeter wave spectral range, than the Doppler linewidth and for this reason these deviations from the Voigt profile can be ignored. Finally, the line mixing effects (Liebe et al., 1992; Tretyakov et al., 2004) were not accounted for in this database because they are negligible for the frequencies and pressures ranges of interest.

The list of lines to be included in the MASTER database could not be limited to the spectral micro-bands (Table I) of MASTER since strong lines far away from the considered spectral bands can have a high contribution to the absorption coefficients. On the other hand it is important to have a reasonable number of lines in the database so that the computing time during the retrieval process remains reasonable. Therefore criteria were adopted for including a given transition in the database. They are as defined in the following:

For a given isotopic species with a "natural" isotopic abundance $a_{\text {ISO }}$ (de Bievre et al., 1984), the lines were introduced in the MASTER linelist if their intensity

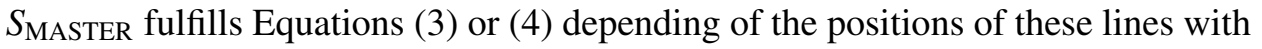
respect to the MASTER spectral bands.

For the lines within the B, C, D, E and F microbands (Table I) or within $\pm 3 \mathrm{GHz}$ of these bands:

$$
S_{\text {MASTER }} a_{\text {iso }} \geq 0.1 \times 10^{-27} \mathrm{~cm}^{-1} /\left(\text { molecule } \mathrm{cm}^{-2}\right)
$$

For the lines falling in the intervals [3-20] GHz away from these bands, the lower limit is:

$$
S_{\text {MASTER }} a_{\text {iso }} \geq 0.1 \times 10^{-22} \mathrm{~cm}^{-1} /\left(\text { molecule } \mathrm{cm}^{-2}\right)
$$


The exceptions are water and the ${ }^{16} \mathrm{O}_{2}$ isotopic species of the oxygen molecule. For both molecules, it is necessary to account for the continuum contribution (Bauer et al., 1986; Godon and Bauer, 1991, 1993, 1995, 1998b; Godon et al., 1992; Liebe 1984, 1985, 1989; Ma et al., 1990; Ma and Tipping, 1992; Ma and Tipping, 2002; Liebe et al., 1992; Tipping and Ma, 1995; Rosenkrantz 1998, 1999; Kuhn et al., 2002) during the retrievals. In order to well model these continua, it is necessary that the database includes a complete line-by-line description for these two molecules. Therefore the MASTER database contains the water lines and ${ }^{16} \mathrm{O}_{2}$ lines which are present in the $0-2,500$ and $45-1,870 \mathrm{GHz}$ frequency ranges, respectively.

Since the problems are specific to each molecule, we describe in the following the choice of the spectral parameters, molecule-by-molecule, giving arguments sustaining the updates.

It is clear, however, that the strongest efforts were devoted to the target species which are gathered in Table I. Finally one should mention that the new database can be easily used to predict atmospheric absorption and radiative transfert in the framework of the public domain Atmospheric Radiative Transfer Simulator program (ARTS) (Buehler et al., 2004).

\section{Status for the Target Species for MASTER ${ }^{1}$}

\subsection{WATER VAPOR $\left(\mathrm{H}_{2} \mathrm{O}\right)$ : MOLECULE 1}

It is clear that because of their rather broad absorption profile, even the water lines located far away from the MASTER microwindows will interfere with the target molecules of MASTER. In addition it is necessary to have a complete water line list in order to account for the water continuum (Liebe 1984, 1985, 1989). Therefore the complete set of water lines (857 transitions belonging to the $\mathrm{H}_{2}{ }^{16} \mathrm{O}, \mathrm{H}_{2}{ }^{18} \mathrm{O}$, $\mathrm{H}_{2}{ }^{17} \mathrm{O}$ and HDO four main isotopic species of water) present in HITRAN in the whole $0-2,500 \mathrm{GHz}$ frequency range were introduced in the MASTER database.

\subsubsection{Line Positions and Line Intensities}

For the water molecule the line positions implemented in the MASTER database are those quoted in the JPL database. This is justified since most of the JPL line positions for the microwave or millimeter wave spectral range are issued from very good line position measurements (de Lucia et al., 1971, 1972a, 1972b, 1974; de Lucia and Helminger, 1975; Matsushima et al., 1995; Messer et al., 1983, 1984; Pearson et al., 1991 and references therein).

On the other hand, it was not obvious to decide which set of water line intensities should be used for MASTER. The HITRAN intensities in the $0-2,500 \mathrm{GHz}$ were generated using a a classical rotational expansion for the dipole moment (Flaud et al., 1981). Actually these intensities differ only marginally from the JPL ones as one could expect since the theoretical approach used to generate these data is 
the same. Therefore in this study we have investigated the quality of the HITRAN intensities by comparing them with new values obtained using a theoretical model developed recently (Coudert, 1994).

Theoretical background. The water molecule is among the lightest molecules and it has very large $A, B$, and $C$ rotational constants equal to $27.88,14.52$, and $9.27 \mathrm{~cm}^{-1}$, respectively. As a consequence, it displays a strong vibration-rotation interaction arising because the rotational energy spacing for quantum numbers as low as eight is of the same order of magnitude than the vibrational energy spacing. The vibrational mode which is the most strongly coupled to the rotation is the bending $v_{2}$ mode as it is the lowest energy vibrational mode $\left(\sim 1,648 \mathrm{~cm}^{-1}\right)$ and as it leads to an infinitely large $A$ rotational constant for a linear configuration of the molecule, i.e., when the bending angle is equal to $180^{\circ}$. This coupling leads to the so-called anomalous centrifugal distortion: when dealing with the rotational energies of water, the usual approach (expansion of the Hamiltonian as a power series of the components of the angular momentum $\mathrm{J}$ ) developed for rigid molecules cannot be safely used because such an expansion diverges for rotational levels with medium and large values of the rotational quantum numbers.

The theoretical approach developed recently (Coudert, 1994) accounts for the strong coupling between the bending $v_{2}$ mode and the overall rotation of the molecule using a four dimensional Hamiltonian in which the overall rotation of the molecule as well as the bending mode are treated together. This approach was successfully used to calculate properly the rotational energies of water (Lanquetin et al., 1999, 2001). In parallel, a model was developed for the line intensities (Coudert, 1999) leading to the determination of a set of dipole moment parameters which are able to reproduce very satisfactorily a large body of intensities from the literature (Toth, 1993a, 1993b, 1998; Rinsland et al., 1991a; Brown and Plymate, 1996).

Validation of the line intensities present in HITRAN. The line intensities in the HITRAN database (denoted HIT in the following) were compared with the line intensities calculated (denoted CALC in the following) using the theoretical approach described above.

For the main isotopic species $\left(\mathrm{H}_{2}{ }^{16} \mathrm{O}\right)$ the results may be summarized in the following way:

- For the pure rotational lines the ratio of intensities HIT/CALC $=1.007(0.016)$ shows that for the set of lines considered there is a very good agreement between the two line lists. This is understandable since the water lines considered here involve low or medium quantum numbers for which centrifugal distortion is rather weak.

- For the rotational lines in the first excited state the ratio of intensities HIT/CALC $=1.034(0.053)$ shows that for the set of lines considered there is still a very good agreement between the two line lists. 
- For the rotational lines in the second excited state the ratio of intensities $(\mathrm{HIT} / \mathrm{CALC}=0.87(23)$ ) shows that for the set of lines considered, the two calculations do not agree very well even if the standard deviation is rather large. It is however difficult to decide without new intensity measurements which line list is better.

For the less abundant isotopic species of $\mathrm{H}_{2} \mathrm{O}$ the lines involve rather low rotational quantum numbers as compared to $\mathrm{H}_{2}{ }^{16} \mathrm{O}$, and it can be expected that the usual approach (Flaud et al., 1981) is working. This was checked on the $\mathrm{H}_{2}{ }^{18} \mathrm{O}$ isotopomer by comparing the intensities of its lines to those of the main isotopomer $\mathrm{H}_{2}{ }^{16} \mathrm{O}$.

As a conclusion one can say that at this stage it is reasonable to use the HITRAN line intensities. For this reason, the line intensities in HITRAN were implemented for water in the MASTER database.

\subsubsection{Line Broadening Coefficients}

The air broadening $\left(\gamma_{\text {air }}^{0}\left(T_{\text {Ref }}\right)\right.$ and $\left.n_{\text {air }}\right)$ coefficients can be found in HITRAN, but these coefficients which are a mixture of a small number of measured values for which the confidence is not always very high (Gamache et al., 1994) and of a larger amount of calculated or estimated values (Gamache and Davies, 1983) which have not been updated for many years are disputable. Furthermore, the self-broadening coefficients are completely missing in HITRAN for the $0-500 \mathrm{~cm}^{-1}$ frequency range.

As a consequence we adopted the following strategy:

- When measurements exist, we use the experimental values. This is the case for:

- The $183 \mathrm{GHz}$ line: (at $298 \mathrm{~K}) \gamma_{\text {air }}=3.84(4) \mathrm{MHz} / \mathrm{Torr}, n_{\text {air }}=0.64(1)$, $\gamma_{\text {self }}=20.0(1) \mathrm{MHz} /$ Torr and $n_{\text {self }}=0.85(5)$ (Bauer et al., 1985, 1989; Goyette and De Lucia, 1990; Tretyakov et al., 2003).

○ The $325.15 \mathrm{GHz}$ line of $\mathrm{H}_{2}^{16} \mathrm{O}: \gamma_{\text {air }}=3.633(30) \mathrm{MHz} / \mathrm{Torr}$ at $300 \mathrm{~K}, n_{\text {air }}=$ 0.640(93) (Colmont et al., 1999).

- The $380.2 \mathrm{GHz}$ line of $\mathrm{H}_{2}{ }^{16} \mathrm{O}: \gamma_{\text {air }}=3.80(4) \mathrm{MHz} /$ Torr at $300 \mathrm{~K}, n_{\text {air }}=$ $0.72(3)$ (Goyette et al., 1993a) and $\gamma_{\text {self }}=20.61(7) \mathrm{MHz} /$ Torr, $n_{\text {self }}=0.89(1)$ (Bauer et al., 1987).

○ The $556 \mathrm{GHz}$ line of $\mathrm{H}_{2}{ }^{16} \mathrm{O}\left(\gamma_{\text {air }}=4.92(6) \mathrm{MHz} / \mathrm{Torr}\right.$ at $297 \mathrm{~K}$ (Markov and Krupnov, 1995).

○ The $203.41 \mathrm{GHz}$ line of $\mathrm{H}_{2}^{18} \mathrm{O}: \gamma_{\text {air }}=3.833(32) \mathrm{MHz} /$ Torr at $300 \mathrm{~K} n_{\text {air }}=$ 0.900(38) (Colmont et al., 1999).

- The HDO lines at $225.896 \mathrm{GHz}\left(\gamma_{\mathrm{air}}=3.85(4) \mathrm{MHz} / \mathrm{Torr}\right.$ at $298 \mathrm{~K}, n_{\mathrm{air}}=$ $0.75(2)), 241.561 \mathrm{GHz}\left(\gamma_{\text {air }}=4.12(4) \mathrm{MHz} /\right.$ Torr at $\left.298 \mathrm{~K}, n_{\text {air }}=0.80(5)\right)$, and $241.973 \mathrm{GHz}\left(\gamma_{\text {air }}=3.08(4) \mathrm{MHz} / \mathrm{Torr}\right.$ at $\left.298 \mathrm{~K}, n_{\text {air }}=0.70(2)\right)$ (Goyette et al., 1993b). 
- For the lines for which line broadening measurements are not available, we used, when the MASTER database was generated the calculated air-broadening and self broadening coefficients given at $T=300 \mathrm{~K}$ together with their $n$ temperature dependence exponents (Bauer et al., 1989). These calculations involve all the $\mathrm{H}_{2}{ }^{16} \mathrm{O}$ strong lines in the $0-1,000 \mathrm{GHz}$ frequency range. In addition, these data were also used for the same rotational transitions of the $\mathrm{H}_{2}{ }^{18} \mathrm{O}$ and $\mathrm{H}_{2}{ }^{17} \mathrm{O}$ isotopic species.

- For future updates of the database it may be necessary to implement the air broadening coefficients issued from the recent calculations at $296 \mathrm{~K}_{\text {of }} \mathrm{N}_{2}$ and $\mathrm{O}_{2}$-broadening coefficients (Gamache and Fischer, 2003a, 2003b; Gamache and Hartmann, 2004) performed for $\mathrm{H}_{2}{ }^{16} \mathrm{O}, \mathrm{H}_{2}{ }^{18} \mathrm{O}, \mathrm{H}_{2}{ }^{17} \mathrm{O}$, HDO and $\mathrm{D}_{2} \mathrm{O}$ using the Complex Robert-Bonamy (CRB) formalism (Gamache et al., 1998). These new calculations were successfully validated using an extended set of measurements (Gamache and Fischer, 2003b). Actually, although the $\mathrm{N}_{2}$ and $\mathrm{O}_{2}$ - broadening parameters differ significantly in Gamache et al. (2003a) from those previously calculated (Bauer et al., 1989), the difference is not so important for the air broadening halfwidths (less than 5\%) for most of the transitions of interest for MASTER. The exceptions are for the transitions involving large $K_{\mathrm{a}}$ values $\left(K_{\mathrm{a}} \approx J \gg K_{\mathrm{c}}\right)$ which are weak lines: in this case the disagreement between the two calculations is larger (up to 8\%). However, to our knowledge, this new calculation does not provide yet for the pure rotation band the $n$-temperature dependence of the air-broadening halfwidths and the self-broadening coefficients which are of importance for MASTER.

- Finally, for the weak lines of water which are in the $0-1,000 \mathrm{GHz}$ range or for all the water lines which are above $1,000 \mathrm{GHz}$, which therefore are expected to interfere only weakly with the lines from the MASTER database, we implement the air-broadening coefficients quoted in HITRAN and the self-broadening coefficients which were deduced from the (empirical) expression (Gamache et al., 1994):

$$
\gamma_{\text {self }}=5 \gamma_{\text {air }}, n_{\text {self }}=1.12 n_{\text {air }}
$$

\subsubsection{Line Shifts}

The data on air shifts for the rotational lines of water are rather sparse. For all water lines for which this parameter is unknown the value $\delta_{\text {air }}=0$ was used in the database. The exceptions concern the lines for which these parameters are available (at about $300 \mathrm{~K}$ ) namely, for $\mathrm{H}_{2}{ }^{18} \mathrm{O}$ the $203.4 \mathrm{GHz}$ line $\left(\delta_{\text {air }}=0.126\right.$ $\mathrm{MHz}$ /Torr, calculated in Colmont et al., 1999), and for $\mathrm{H}_{2}{ }^{16} \mathrm{O}$, the lines located at $183 \mathrm{GHz}\left(\delta_{\text {air }}=-0.067(20) \mathrm{MHz} / \mathrm{Torr}\right.$, measured in Tretyakov et al., 2003), $325.1 \mathrm{GHz}\left(\delta_{\text {air }}=-0.15 \mathrm{MHz} /\right.$ Torr, calculated in Colmont et al., 1999) and 556 $\mathrm{GHz}\left(\delta_{\text {air }}=+0.300(4) \mathrm{MHz} / \mathrm{Torr}\right.$, measured in Markov and Krupnov, 1995). One should mention that an improvement in the UARS-MLS retrievals was ob- 
tained when considering $\delta_{\text {air }}$ for the $183 \mathrm{GHz}$ line of water (Pumphrey et al., 2000).

\subsection{OZONE $\left(\mathrm{O}_{3}\right)$ : MOLECULE 3}

\subsubsection{Line Positions}

For the line positions and lower state energies, we used the JPL values (Depannemaeker and Bellet, 1977; Pickett et al., 1985; Pickett et al., 1988) with the exception of the $2^{1} \leftrightarrow 2^{1}$ transitions of the ${ }^{16} \mathrm{O}^{18} \mathrm{O}^{16} \mathrm{O}$ and ${ }^{16} \mathrm{O}^{16} \mathrm{O}^{18} \mathrm{O}$ isotopic species for which the lower energy levels are incorrect. For these transitions we have used the HITRAN values (Flaud et al., 1990a).

\subsubsection{Line Intensities}

For ozone, the centrifugal distortion effects which affect the line intensities in the microwave spectral region appear as a rotational dependence of the dipole moment operator expansion in the ground vibrational state (Pickett et al., 1985; Flaud et al., 1990a; Flaud and Bacis, 1998a). Such an effect was accounted for by expanding the dipole moment up to the second order with respect to rotational operators (See the Table VIII in Flaud et al., 1990a). The ozone line intensities resulting from this calculation (Flaud et al., 1990a) are presently implemented in the HITRAN database. Since that time the main changes have concerned a likely better evaluation (Flaud et al., 1990b; Birk et al. 1994a, 1994b; Claveau et al., 2001; de Backer-Barilly and Barbe, 2001; Wagner et al., 2002; Flaud et al., 2003a) of the first derivatives of the dipole moment coefficients ${ }^{\alpha} \mu_{\mathrm{m}}$ of Table VIII in Flaud et al. (1990a). Table II gives the new values of these coefficients as well as the previous ones and the corresponding changes.

Such changes (of the order of $1 \%$ ) translate in analogous changes in the (second order) correcting rotational terms appearing in the expansion of the effective dipole moment in the ground state (Table VIII in Flaud et al., 1990a).

Table II. Change in the values of the first order derivatives of the ozone dipole moment (in Debye)

\begin{tabular}{|c|c|c|c|}
\hline Coefficient & $\begin{array}{l}\text { New value (Claveau } \text { et al., 2001; } \\
\text { de Backer-Barilly et al., 2001; } \\
\text { Wagner } \text { et al., 2002; Flaud } \text { et al., 2003a) }\end{array}$ & $\begin{array}{l}\text { Previous value } \\
\text { (Flaud } \text { et al., 1990a) }\end{array}$ & Change (\%) \\
\hline${ }^{x} \mu_{1}$ & -0.02150 & -0.02185 & -1.6 \\
\hline${ }^{x} \mu_{2}$ & -0.06483 & -0.06529 & -0.7 \\
\hline${ }^{z} \mu_{3}$ & -0.2630 & -0.2662 & -1.2 \\
\hline
\end{tabular}


Given the order of magnitude of these terms, assuming maximum values of 80-100 for the rotational quantum numbers $J$ or $K_{\mathrm{a}}$ leads to a change smaller than $0.1 \%$ in the line intensities and this for the weakest lines. As a consequence, given the present knowledge of the $\mathrm{O}_{3}$ dipole moment, one can say that the intensities quoted in HITRAN are the best that one can generate. As a consequence the HITRAN line intensities were introduced in the MASTER database.

\subsubsection{Line Broadening Coefficients}

As for $\mathrm{H}_{2} \mathrm{O}$, we have used, when available, experimental values for the airbroadening coefficients. More precisely for the lines of ${ }^{16} \mathrm{O}_{3}$ located at 497.1, $498.7,500.2,501.8,505.26 \mathrm{GHz}$ we used the line broadening coefficients which were derived during a previous study (Bauer et al., 1998a; Priem et al., 2000b; Birk et al., 1997). For the lines at 288.96, 610.37 and $625.37 \mathrm{GHz}$, we used calculated values for $\gamma_{\text {air }}$ and $n_{\text {air }}$ (Drouin et al., 2004b). For the lines at 300.7, 301.8, 303.2, $317.2,343.2$ and $343.5 \mathrm{GHz}$ we used the line broadening coefficients measured within the course of this study (Demaison et al., 2004). All these data are collected in Table III.

It is generally recognized that the vibrational dependence of the line broadening coefficients for ozone is rather weak. Also the isotopic dependence for the broadening coefficients is assumed to be negligible. Accordingly, the available experimental $\gamma_{\text {air }}$ values were used for the various hot bands transitions of ozone and for the less abundant isotopic species. Finally, for all the other lines the broadening coefficients are issued from the HITRAN database.

The $n$-temperature dependences of the linewidths which are collected in Table III were incorporated in the database. For the other lines, the value $n_{\text {air }}=0.76$ (as in HITRAN) was used for the $n$-temperature dependence of the air-halfwidths. Finally the self broadening coefficients $\gamma_{\text {self }}$ quoted in HITRAN were implemented for the lines present in the MASTER database. For the ozone lines absent in HITRAN, we set $\gamma_{\text {self }} \sim 4 \mathrm{MHz} /$ Torr together with $n_{\text {self }}=0.7$, these values being the average values obtained recently (Larsen et al., 2001).

\subsubsection{Line Shifts}

Table III collects the existing pressure shifts data for ozone in the microwave region for the lines of MASTER interest. Additional informations are also given in (Drouin et al., 2004b). It is clear that this effect is rather weak and therefore the value $\delta_{\text {air }}=0$ was stated in the database for all lines of MASTER. 
Table III. List of the line broadening data collected for ozone in the MASTER database

\begin{tabular}{llrlrrlrllll}
\hline & $v$ & $J^{\prime}$ & $K_{\mathrm{a}}{ }^{\prime}$ & $K_{\mathrm{c}}{ }^{\prime}$ & $J^{\prime \prime}$ & $K_{\mathrm{a}}^{\prime \prime}$ & $K_{\mathrm{c}}{ }^{\prime \prime}$ & $T(\mathrm{~K})$ & $\gamma_{\text {air }}$ & $n_{\text {air }}$ & $\delta_{\text {air }}$ \\
\hline $\mathrm{L}$ & 300685 & 13 & 4 & 10 & 14 & 3 & 10 & 238 & $3.730(18)$ & & \\
$\mathrm{L}+\mathrm{B}$ & 301813 & 14 & 0 & 14 & 13 & 1 & 13 & 296 & $3.081(19)$ & $0.676(20)$ & $10(2)$ \\
$\mathrm{L}$ & 303165 & 7 & 2 & 6 & 7 & 1 & 7 & 296 & $3.287(19)$ & & \\
$\mathrm{B}+\mathrm{L}$ & 317195 & 5 & 3 & 3 & 6 & 2 & 4 & 296 & $3.427(29)$ & & \\
$\mathrm{B}$ & 317195 & 5 & 3 & 3 & 6 & 2 & 4 & 240 & $3.888(6)$ & & $13(1)$ \\
$\mathrm{B}$ & 319997 & 20 & 1 & 19 & 20 & 0 & 20 & 296 & $2.951(10)$ & $0.722(13)$ & $28.2(5)$ \\
$\mathrm{L}$ & 343238 & 26 & 2 & 24 & 25 & 3 & 23 & 240 & $3.583(26)$ & & \\
$\mathrm{L}$ & 343506 & 4 & 3 & 1 & 5 & 2 & 4 & 240 & $3.682(30)$ & & \\
$\mathrm{Ba}$ & 497098 & 23 & 2 & 22 & 23 & 1 & 23 & 240 & $3.27(3)$ & $0.81(5)$ & \\
$\mathrm{Ba}$ & 498747 & 24 & 1 & 23 & 23 & 2 & 22 & 240 & $3.34(1)$ & $0.74(2)$ & \\
$\mathrm{Ba}$ & 501771 & 48 & 4 & 44 & 48 & 3 & 45 & 240 & $3.28(3)$ & $0.78(6)$ & \\
$\mathrm{Ba}$ & 505257 & 5 & 4 & 2 & 6 & 3 & 3 & 240 & $3.10(4)$ & $0.76(6)$ & \\
$\mathrm{P}$ & 500433 & 34 & 2 & 32 & 34 & 1 & 33 & 240 & $3.362(20)$ & $0.876(80)$ & \\
$\mathrm{D}$ & 288959 & 9 & 1 & 9 & 8 & 0 & 8 & 296 & 3.172 & 0.806 & -1 \\
$\mathrm{D}$ & 610365 & 25 & 1 & 25 & 24 & 0 & 24 & 296 & 2.756 & 0.790 & -8 \\
$\mathrm{D}$ & 625371 & 15 & 6 & 10 & 16 & 5 & 11 & 296 & 3.011 & 0.77 & -4 \\
\hline
\end{tabular}

$\mathrm{L}$ and B: Measurements performed within the course of the experimental study performed in Lille (L) and Bologne (B) (Demaison et al., 2004); P: Measurements from (Priem et al., 2000b); Ba: Measurements from (Bauer et al., 1998a); D: Calculated data from (Drouin et al., $2004 \mathrm{~b}) ; \tilde{v}$ : line position in $\mathrm{MHz}, J^{\prime} K_{\mathrm{a}}{ }^{\prime} K_{\mathrm{c}}{ }^{\prime} J^{\prime \prime} K_{\mathrm{a}}{ }^{\prime \prime} K_{\mathrm{c}}{ }^{\prime \prime}$ upper and lower rotational quantum numbers; $T$ : temperature for the measurements; $\gamma_{\text {air }}$ : air-pressure broadening coefficient (in $\mathrm{MHz} / \mathrm{Torr}) ; n_{\text {air }}:$ temperature dependence; $\delta_{\text {air }}$ : air-pressure shift (in kHz/Torr).

\subsection{NITROUS OXIDE $\left(\mathrm{N}_{2} \mathrm{O}\right)$ : MOLECULE 4}

\subsubsection{Line Positions}

$\mathrm{N}_{2} \mathrm{O}$ has been the subject of numerous studies (Lovas, 1978; Reinartz et al., 1978; Teffo et al., 1994; Lyulin, 1995; Lovas, 2004). Therefore, the experimental line positions gathered in the compilations performed by Lovas (Lovas, 1978, 2004) have been included in the JPL database.

For the MASTER database which involves lines belonging to ${ }^{14} \mathrm{~N}^{14} \mathrm{~N}^{16} \mathrm{O}$ and to the two minor species, ${ }^{14} \mathrm{~N}^{15} \mathrm{~N}^{16} \mathrm{O}$ and ${ }^{15} \mathrm{~N}^{14} \mathrm{~N}^{16} \mathrm{O}$, we have used the JPL line positions for the transitions within the ground vibrational state and within the first

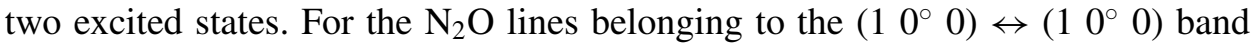
we have used the HITRAN line positions because such transitions are absent in the JPL database.

\subsubsection{Line Intensities}

For nitrous oxide, the line intensities calculation for microwave transitions can be performed without considering Herman-Wallis effect. The line intensities in the 
JPL catalog were generated using the value of the permanent dipole moment $\mu_{0}$ which was measured with a good accuracy by Stark effect (Scharpen et al., 1970). On the other hand, the vibrational contribution to the $\mathrm{N}_{2} \mathrm{O}$ partition function which is $Z_{\mathrm{Vib}}(T)=1.1340$ at $T=300 \mathrm{~K}$ was neglected, and therefore the line intensities in the JPL catalog are overestimated by $\sim 13 \%$.

To solve this problem, a new intensity calculation was performed using the $\mathrm{N}_{2} \mathrm{O}$ dipole moment (Scharpen et al., 1970) and the HITRAN partition function. The new intensities are (as expected) $\sim 13 \%$ weaker than those in the JPL catalog, but on the other hand, also about $\sim 7 \%$ weaker than the HITRAN ones. The reasons for this disagreement are still not clear because we did not succeed to identify the origin of the HITRAN data.

Given these comments we have implemented in the MASTER database the $\mathrm{N}_{2} \mathrm{O}$ intensities generated from this study.

\subsubsection{Line Broadening Coefficients}

For the air-broadening coefficients $\gamma_{\text {air }}$ and its temperature dependence we used the values quoted in the HITRAN database. The exceptions are the lines of interest for MASTER for which broadening measurements exist, namely the 301.443 and $301.422 \mathrm{GHz}$ lines (R11 lines of the ${ }^{14} \mathrm{~N}_{2}^{16} \mathrm{O}$ and ${ }^{14} \mathrm{~N}^{15} \mathrm{~N}^{16} \mathrm{O}$ isotopomers, respectively) for which we implemented the value $\gamma_{\text {air }}=3.148(14) \mathrm{MHz} /$ Torr at $296 \mathrm{~K}$ (Demaison et al., 2004), and the line at $627.751 \mathrm{GHz}\left(\gamma_{\text {air }}=2.87(10) \mathrm{MHz} /\right.$ Torr at $294 \mathrm{~K}$ ) (Morino and Yamada, 2003). Outside MASTER frequency range, additional line broadening coefficients were measured for the 201, 552 and $577 \mathrm{GHz}$ millimeter lines (Rohart et al., 2003).

For the self-broadening coefficients and their temperature dependence, we used $\gamma_{\text {self }}=4 \mathrm{MHz} /$ Torr and $n_{\text {self }}=0.7$ which are mean values for these parameters according to various infrared (Lacome et al., 1983; Toth 1993c) and microwave measurements (Colmont and Semmoud-Monnanteuil, 1987; Morino and Yamada, 2003).

\subsection{CARBON MONOXIDE (CO): MOLECULE 5}

Numerous line positions and intensities measurements were performed both in the microwave and in the infrared spectral range (Winnewisser et al., 1997; Cazzoli et al., 2002a, 2002b; Klapper et al., 2000a, 2000b, 2001). As far as the MASTER database is concerned ${ }^{12} \mathrm{C}^{16} \mathrm{O}$ will be measured using the R2 line whose line position was measured at $345795.98(5) \mathrm{MHz}$ with high accuracy by Nolt et al. (1987).

When dealing with line intensities, two measurements of the CO dipole moment were performed by Stark effect leading to fully compatible results (Muenter, 1975; Meerts et al., 1977). These data were used to generate the accurate intensities quoted in the JPL database for CO. 
For the $345.8 \mathrm{GHz}$ line of $\mathrm{CO}$, measurements of the $\mathrm{N}_{2}$ - and $\mathrm{O}_{2}$ - line broadening coefficients were performed (Priem et al., 2000a; Birk et al., 1997; Bauer et al., 1998a) leading to the values $\gamma_{\text {air }}=2.728(17) \mathrm{MHz} /$ Torr (at $296 \mathrm{~K}$ ) and $n_{\text {air }}=$ $0.864(36)$.

\subsection{MOLECULAR OXYGEN (THE ${ }^{18} \mathrm{O}^{16} \mathrm{O},{ }^{17} \mathrm{O}^{16} \mathrm{O}$ AND ${ }^{16} \mathrm{O}_{2}$ ISOTOPIC SPECIES): MOLECULE 7}

For the ${ }^{16} \mathrm{O}_{2},{ }^{18} \mathrm{O}^{16} \mathrm{O}$ and ${ }^{17} \mathrm{O}^{16} \mathrm{O}$ isotopic species, we used the JPL line positions and intensities. These line positions are of excellent quality, since they were measured extensively (Krupenie 1972; Amano and Hirota, 1974; Steinbach and Gordy, 1975; Cazzoli et al., 1981; Zink and Mizushima, 1987; Crownover et al., 1990; Mizushima and Yamamoto, 1991; Golubiatnikov and Krupnov, 2003 and references therein), and the line intensities are in excellent agreement with the HITRAN's ones.

For ${ }^{16} \mathrm{O}_{2}$ we used ${ }^{2}$ the $\mathrm{N}_{2}$ - and $\mathrm{O}_{2}$-broadening coefficients measured recently (Krupnov et al., 2002; Tretyakov et al., 2004). For $\mathrm{O}^{18} \mathrm{O}^{16}$, the broadening coefficients were estimated from those of rotational transitions involving similar quantum numbers of the ${ }^{16} \mathrm{O}_{2}$ isotopic species (Krupnov et al., 2002; Tretyakov et al., 2004). These values are quoted in Table IV for $\mathrm{O}^{18} \mathrm{O}^{16}$. For the less abundant $\mathrm{O}^{17} \mathrm{O}^{16}$ species, the rotational dependence of the linewidths was not accounted for and the average values $\gamma_{\mathrm{N} 2} \approx 2.2 \mathrm{MHz} /$ Torr and $\gamma_{\mathrm{O} 2} \approx 2.10 \mathrm{MHz} /$ Torr were implemented for all the lines.

Finally, it has to be mentioned that the earth magnetic field leads to Zeeman effects which may modify the profile of oxygen lines. For example, a $\pm 2.5 \mathrm{MHz}$ substructure for the $2_{1} \leftarrow 0_{1}$ rotational transition of ${ }^{16} \mathrm{O}^{18} \mathrm{O}$ located at $233.9 \mathrm{GHz}$ was observed during ground measurement by the $2.5 \mathrm{~m}$-radiotelescope POM2 located at "Plateau de Bure" in the French Alps (Pardo et al., 1995; Sandor and Clancy, 1997). In addition line mixing may occur in the $Q$-branches as it was also pointed out for ${ }^{16} \mathrm{O}_{2}$ at $60 \mathrm{GHz}$ (Liebe et al., 1992) and 118 $\mathrm{GHz}$ (Tretyakov et al., 2004). These two effects may be of importance for the retrievals.

Table IV. Broadening parameters (in MHz/TORR) implemented in MASTER for the ${ }^{18} \mathrm{O}^{16} \mathrm{O}(T=295$ K)

\begin{tabular}{llll}
\hline Frequency in $\mathrm{GHz}$ & $\gamma_{\mathrm{N}_{2}}$ & $\gamma_{\mathrm{O}_{2}}$ & $\mathrm{~N}^{\prime}, J^{\prime} \leftarrow \mathrm{N}^{\prime \prime} J^{\prime \prime}$ \\
\hline 298 & 2.30 & 2.25 & $22 \leftarrow 01$ \\
345 & 2.21 & 2.19 & $32 \leftarrow 11$ \\
508 & 2.15 & 2.10 & $43 \leftarrow 22$ \\
627 & 2.15 & 2.10 & $44 \leftarrow 23$ \\
\hline
\end{tabular}




\subsection{NITRIC ACID $\left(\mathrm{HNO}_{3}\right)$ : MOLECULE 12}

For the description of the nitric acid contribution in the spectral ranges of MASTER it is necessary to take into account a large number of lines because of the low values of the rotational parameters of this molecule $(A \sim B \sim 13$ $\mathrm{GHz}, C \sim 6.2 \mathrm{GHz}$ ). In addition, the first vibrational states of nitric acid $9^{1}$, $7^{1}, 6^{1}, 8^{1}, 5^{1}$ and $9^{2}$ are located at rather low energies, i.e. at 458, 580, 647, 763,879 , and $896 \mathrm{~cm}^{-1}$ respectively. Therefore the transitions within $9^{1}, 7^{1}, 6^{1}$, $8^{1}, 5^{1}$ and $9^{2}$ (hereafter referred as "hot" transitions) contribute at $296 \mathrm{~K}$ for about $23 \%$ to the total $\mathrm{HNO}_{3}$ line intensities and are to be considered in addition to those within the ground vibrational state (hereafter referred as "cold transitions").

Numerous recent microwave or millimeter studies involve line position studies for transitions not only in the ground vibrational state but also in the $9^{1}, 7^{1}, 6^{1}, 8^{1}$, $5^{1}$ and $9^{2}$ vibrational states (Cazzoli and De Lucia, 1979; Crownover et al., 1988; Paulse et al., 1996; Goyette et al., 1996; Petkie et al., 2001, 2003; Perrin 1998b; Perrin et al., 2004). It is important to underline that some of these studies had to take into the fact that the $v_{9}$ mode located at $458 \mathrm{~cm}^{-1}(\mathrm{OH}$ torsional mode relative to the $\mathrm{NO}_{2}$ moiety) is a "large amplitude motion". This effect induces indeed splittings of about 2,35 and $51 \mathrm{MHz}$ for the energy levels in the $9^{1}, 5^{1}$, and $9^{2}$ vibrational states, respectively.

\subsection{1. $\mathrm{HNO}_{3}$ Line Positions and Intensities in the HITRAN and JPL Databases}

In the JPL database the quoted lines involve hot transitions within $9^{1}, 6^{1}, 7^{1}$, $8^{1}, 5^{1}$ and $9^{2}$ in addition with the cold transitions. However, the line positions for the $9^{1} \leftrightarrow 9^{1}, 5^{1} \leftrightarrow 5^{1}, 9^{2} \leftrightarrow 9^{2}, 5^{1} \leftrightarrow 9^{2}$ and $9^{2} \leftrightarrow 5^{1}$ transitions are not accurate since the JPL calculations were performed around 1990 when the theoretical model able to handle the torsional effects was not yet developed.

The line intensities in the JPL catalog were generated using a dipole moment $\mu_{0}$ derived from various Stark concurring measurements (Cox and Riveros, 1965; Kleiner et al., 1987). On the other hand, and as for $\mathrm{N}_{2} \mathrm{O}$ only the rotational part of the partition function was accounted for in the JPL calculation: see Table $\mathrm{V}$ where a comparison of the partition functions used in HITRAN (Fischer et al., 2003) and in the JPL catalog is given. Because of the existence of rather low vibrational states for $\mathrm{HNO}_{3}$, the vibrational part of the partition function contributes for about $30 \%$ at $T=296 \mathrm{~K}\left(Z_{\mathrm{Vib}}(300 \mathrm{~K}) \sim 1.3\right)$ to the total partition function, leading to JPL intensities for $\mathrm{HNO}_{3}$ overestimated by about 30\%. The situation is not better in HITRAN since the positions and intensities parameters (Rothman et al., 1983) are only a 1983 version of the JPL catalog. 
Table V. Comparison of the partition function for nitric acid calculated in this work and in the HITRAN and JPL databases. For the present calculation, the vibrational and rotational contributions are given

\begin{tabular}{rlllrr}
\hline Temp & $Z_{\text {Rot }}$ & $Z_{\text {Vib }}$ & \multicolumn{1}{l}{$Z_{\text {Tot }}$} & $Z$ (JPL) & \multicolumn{1}{l}{$Z$ (HITRAN) } \\
\hline 75 & 3493.79 & 1.00017 & 3494.39 & 3493.8 & 3496.2 \\
150 & 9879.18 & 1.01933 & 10070.2 & 9878.7 & 10080.0 \\
225 & 18151.0 & 1.11344 & 20210.1 & 18151.0 & 20244.7 \\
296 & 27363.6 & 1.29952 & 35559.6 & & 35687.8 \\
300 & 27917.4 & 1.31316 & 36660.1 & 27938.3 & 36797.9 \\
\hline
\end{tabular}

\subsection{2. $\mathrm{HNO}_{3}$ Line Positions and Intensities in the MASTER Database}

Given the previous comments, a new list of $\mathrm{HNO}_{3}$ line positions and intensities was generated for MASTER. For the cold band and transitions within the $6^{1}, 7^{1}$, and $8^{1}$ excited vibrational states, no perturbations had to be accounted for. Therefore we used a classical method of calculation both for line positions (Watson, 1977) and line intensities (Flaud et al., 1981), and the rotational and centrifugal distortion parameters from Petkie et al. (2003), the $\mathrm{HNO}_{3}$ dipole moment (Cox and Riveros, 1965 ) and the partition function quoted in HITRAN (Fischer et al., 2003). For the $9^{1} \leftrightarrow 9^{1}, 5^{1} \leftrightarrow 5^{1}, 9^{2} \leftrightarrow 9^{2}, 5^{1} \leftrightarrow 9^{2}$ and $9^{2} \leftrightarrow 5^{1}$ transitions, we had to account for the torsional effect. This was done using the Internal Axis Method (IAM) both for the line position and line intensity calculations. For these computations we used the rotational, torsional and coupling parameters which are quoted by Paulse et al. (1996) and by Perrin et al. (2004) for the $9^{1}$ and $5^{1}, 9^{2}$ vibrational states respectively.

To illustrate these results, a comparison is performed in Table VI for the $9^{1} \leftrightarrow 9^{1}$ "hot" band of $\mathrm{HNO}_{3}$ in the $343,799-343,835 \mathrm{MHz}$ region. In this case the line positions calculated using the parameters from (Paulse et al., 1996) differ from those present in JPL because the torsional splitting is now accounted for correctly. Also, the JPL linelist involves eight transitions, but for symmetry reasons, only four transitions (instead of eight) actually exist (Paulse et al., 1996).

\subsection{3. $\mathrm{HNO}_{3}$ Line Broadening Coefficients}

The only existing $\mathrm{N}_{2}$ - and $\mathrm{O}_{2}$-line broadening calculation was performed a long time ago by Tejwani and Yeung (1978). Since this early work performed using the Anderson theory, to our knowledge no new line broadening calculation was published.

There exist few line broadening measurements for $\mathrm{HNO}_{3}$. The most accurate were performed in the microwave or submillimeter spectral region by Goyette et al. (1988a, 1991, 1998), Zu et al. (2002), and Colmont et al. (2003), because these measurements were performed for well-isolated lines. In order to complete 
Table VI. Portion of the JPL line list for the $9^{1}-9^{1}$ transitions of $\mathrm{HNO}_{3}$ in the $343.7-343.9$ $\mathrm{GHz}$ region and comparison with the observed positions and with the calculation (positions and intensities) performed in the present study

\begin{tabular}{lllllllllllll}
\hline & $\begin{array}{l}\text { Int } \times 10^{+23} \\
\text { JPL }\end{array}$ & $\begin{array}{l}v_{\text {Obs }}(\text { Paulse } \\
\text { et al., 1996) }\end{array}$ & $\begin{array}{l}v_{\text {Calc }} \\
\text { (This work) }\end{array}$ & $\begin{array}{l}\text { Int } \times 10^{+23} \\
\text { (This work) }\end{array}$ & $J^{\prime}$ & $K_{\mathrm{a}}^{\prime}$ & $K_{\mathrm{c}}^{\prime}$ & $J^{\prime \prime}$ & $K_{\mathrm{a}}^{\prime \prime}$ & $K_{\mathrm{c}}{ }^{\prime \prime}$ \\
\hline 343823.7959 & 0.19 & 343826.189 & 343826.056 & 1.46 & 18 & 9 & 9 & 17 & 10 & 8 \\
343826.9947 & 0.19 & & & & & & & & & & & \\
343826.1411 & 1.25 & 343827.162 & 343827.074 & 0.741 & 18 & 10 & 9 & 17 & 10 & 8 \\
343826.1468 & 1.25 & & & & & & & & & \\
343832.2270 & 1.25 & 343831.089 & 343831.164 & 0.741 & 18 & 9 & 9 & 17 & 9 & 8 \\
343832.2326 & 1.25 & & & & & & & & & \\
343831.3791 & 0.19 & 343832.219 & 343832.182 & 1.46 & 18 & 10 & 9 & 17 & 9 & 8 \\
343834.5778 & 0.19 & & & & & & & & & & \\
\hline
\end{tabular}

Note. As compared to the JPL list, only every other line is existing for symmetry reasons. Other details on the intensity calculations are given in the text. All the intensities are in $\mathrm{cm}^{-1} /\left(\right.$ molecule $\left.\mathrm{cm}^{-2}\right)$ at $296 \mathrm{~K}$.

these studies, air-broadening measurements were performed in Lille and Bologna (Demaison et al., 2004; Cazzoli et al., 2005). Depending on the rotational transition, the nitrogen- and oxygen-broadening coefficients range between $4.17 \mathrm{MHz} / \mathrm{Torr}$ and 4.88 MHz/Torr for $\gamma_{\mathrm{N} 2}$, and between $2.31 \mathrm{MHz} /$ Torr and $2.96 \mathrm{MHz} /$ Torr for $\gamma_{\mathrm{O} 2}$. Table VII gives a list of air broadening halfwidths for various pure rotational transitions in the microwave or millimeter regions, and it is clear also, from this table that there exists a rather clear rotational dependence of the air broadening coefficients which need to be modeled.

We used an empirical model which is defined as follows.

For low and medium $J^{\prime \prime}$ values:

$$
\gamma_{\text {air }}=a_{\text {air }}+b_{\text {air }}\left(J^{\prime}+J^{\prime \prime}\right) / 2
$$

For high $J^{\prime \prime}$ values $\left(\left(J^{\prime}+J^{\prime \prime}\right) / 2>J^{\mathrm{MAX}}\right)$, we used (more or less) a "hard spheres" collisions model:

$$
\gamma_{\text {air }}=\text { constant }
$$

This model is presented in Figure 1 . In order to determine $a_{\text {air }}, b_{\text {air }}$ and $J^{\text {Max }}$, a least squares fit calculation was performed on the experimental data quoted in Table VII. The results of this computation are (in MHz/Torr for $a_{\text {air }}$ and $b_{\text {air }}$ ):

$$
J^{\mathrm{MAX}}=34.402 \pm 5, \alpha_{\text {air }}=5.04875 \pm 0.20, \text { and } b_{\text {air }}=0.0340645 \pm 0.009
$$

The inspection of Table VII and Figure 1 shows that the empirical model is working reasonably well. As a consequence Equations (6), (7) and (8) were used 
Table VII. List of the air-broadening experimental coefficients used for the empirical description of the broadening coefficients of $\mathrm{HNO}_{3}$. Results of the calculation

\begin{tabular}{|c|c|c|c|c|c|c|c|c|c|}
\hline$v$ & $J^{\prime}$ & $K_{\mathrm{a}}{ }^{\prime}$ & $K_{\mathrm{c}}^{\prime}$ & $J^{\prime \prime}$ & $K_{\mathrm{a}}^{\prime \prime}$ & $K_{\mathrm{c}}^{\prime \prime}$ & $\gamma_{\text {airObs }}$ & $\gamma_{\text {airCalc }}$ & Ref. \\
\hline 231778 & 14 & $\mathrm{~d}$ & 10 & 13 & d & 9 & 4.599 & 4.589 & (Goyette et al., 1988a) \\
\hline 281782 & 19 & $\mathrm{~d}$ & 16 & 18 & $\mathrm{~d}$ & 15 & 4.311 & 4.419 & (Goyette et al., 1988a) \\
\hline 281685 & 22 & $\mathrm{~d}$ & 22 & 21 & d & 21 & 3.909 & 4.316 & (Goyette et al., 1988a) \\
\hline 444556 & 26 & $\mathrm{~d}$ & 17 & 25 & $\mathrm{~d}$ & 16 & 4.11 & 4.180 & (Goyette et al., 1988a) \\
\hline 457042 & 27 & 9 & 18 & 26 & 9 & 17 & 3.989 & 4.146 & (Goyette et al., 1988a) \\
\hline 444284 & 35 & $\mathrm{~d}$ & 35 & 34 & d & 34 & 3.851 & 3.877 & (Goyette et al., 1988a) \\
\hline 456784 & 36 & $\mathrm{~d}$ & 36 & 35 & $\mathrm{~d}$ & 35 & 3.954 & 3.877 & (Goyette et al., 1988a) \\
\hline 235168 & 11 & 9 & 3 & 10 & 9 & 2 & 4.355 & 4.691 & (Goyette et al., 1988a) \\
\hline 232179 & 12 & 6 & 6 & 11 & 6 & 5 & 4.93 & 4.657 & (Goyette et al., 1988a) \\
\hline 284871 & 13 & 11 & 2 & 12 & 11 & 1 & 4.566 & 4.623 & (Goyette et al., 1988a) \\
\hline 283003 & 14 & 8 & 6 & 13 & 8 & 5 & 4.590 & 4.589 & (Goyette et al., 1988a) \\
\hline 370541 & 18 & 12 & 7 & 17 & 12 & 6 & 4.428 & 4.453 & (Goyette et al., 1988a) \\
\hline 453822 & 20 & 15 & 5 & 19 & 15 & 4 & 3.747 & 4.384 & (Goyette et al., 1988a) \\
\hline 231627 & 18 & $\mathrm{~d}$ & 18 & 17 & d & 17 & 4.353 & 4.453 & (Goyette et al., 1991) \\
\hline 369487 & 22 & d & 15 & 21 & $\mathrm{~d}$ & 14 & 4.229 & 4.316 & (Goyette et al., 1991) \\
\hline 369258 & 29 & $\mathrm{~d}$ & 29 & 28 & d & 28 & 3.929 & 4.078 & (Goyette et al., 1991) \\
\hline 206595 & 16 & $\mathrm{~d}$ & 16 & 15 & $\mathrm{~d}$ & 15 & 4.428 & 4.521 & (Goyette et al., 1998) \\
\hline 206663 & 14 & $\mathrm{~d}$ & 12 & 13 & 2 & 11 & 4.752 & 4.589 & (Goyette et al., 1998) \\
\hline 206703 & 13 & $\mathrm{~d}$ & 10 & 12 & 3 & 9 & 4.824 & 4.623 & (Goyette et al., 1998) \\
\hline 219037 & 24 & $\mathrm{~d}$ & 17 & 24 & 8 & 16 & 4.215 & 4.231 & (Goyette et al., 1998) \\
\hline 218896 & 25 & $\mathrm{~d}$ & 17 & 25 & 9 & 16 & 4.343 & 4.197 & (Goyette et al., 1998) \\
\hline 218739 & 26 & 10 & 17 & 26 & 10 & 16 & 4.221 & 4.163 & (Goyette et al., 1998) \\
\hline 206765 & 12 & 5 & 8 & 11 & 5 & 7 & 4.689 & 4.657 & (Goyette et al., 1998) \\
\hline 205120 & 30 & 14 & 16 & 30 & 14 & 17 & 4.198 & 4.027 & (Goyette et al., 1998) \\
\hline 686636 & 32 & 28 & 4 & 31 & 28 & 3 & 3.916 & 3.976 & (Zu et al., 2002) \\
\hline 686579 & 32 & 28 & 5 & 31 & 28 & 4 & 4.337 & 3.976 & (Zu et al., 2002) \\
\hline 686157 & 32 & 23 & 10 & 31 & 23 & 9 & 4.01 & 3.976 & (Zu et al., 2002) \\
\hline 684157 & 31 & 22 & 9 & 30 & 22 & 8 & 4.171 & 4.010 & (Zu et al., 2002) \\
\hline 316611 & 44 & 19 & 25 & 44 & 18 & 26 & 3.832 & 3.877 & Lille \\
\hline 316902 & 43 & 19 & 25 & 43 & 17 & 26 & 3.82 & 3.877 & Lille \\
\hline 344241 & 27 & d & 27 & 26 & $\mathrm{~d}$ & 26 & 4.182 & 4.146 & Lille + Bologna \\
\hline 470233 & 24 & 13 & 11 & 23 & 13 & 10 & 4.16 & 4.248 & Lille \\
\hline 544365 & 38 & 5 & 33 & 37 & 5 & 32 & 3.92 & 3.877 & Lille \\
\hline 206663 & 14 & 2 & 12 & 13 & 2 & 11 & 4.881 & 4.589 & Lille \\
\hline 319221 & 25 & 0 & 25 & 24 & 0 & 24 & 4.192 & 4.214 & Bologna \\
\hline 319897 & 27 & 2 & 25 & 27 & 1 & 27 & 4.282 & 4.129 & Bologna \\
\hline 320005 & 26 & 1 & 25 & 26 & 0 & 26 & 4.211 & 4.163 & Bologna \\
\hline 322348 & 15 & 13 & 3 & 14 & 13 & 2 & 4.574 & 4.555 & Bologna \\
\hline
\end{tabular}

Note. Meaning of the different columns: $\tilde{v}$ : frequency in $\mathrm{MHz} ; J^{\prime} K_{\mathrm{a}}{ }^{\prime} K_{\mathrm{c}}{ }^{\prime} J^{\prime \prime} K_{\mathrm{a}}{ }^{\prime \prime} K_{\mathrm{c}}{ }^{\prime \prime}$ : upper and lower rotational quantum numbers, $\mathrm{d}$ is for degenerate doublets $\left(K_{\mathrm{a}}=J-K_{\mathrm{c}}\right.$ and $\left.J-K_{\mathrm{c}}+1\right) ; \gamma_{\text {air }}$ observed and calculated air-pressure broadening coefficients (in MHz/Torr at $296 \mathrm{~K})$; Ref.: source of the data, Lille and Bologna are for the measurements described by Demaison et al. (2004). 
Table VIII. Comparison between the $\mathrm{BrO}$ partition function achieved in this work and those quoted in the JPL catalog

\begin{tabular}{lllllll}
\hline$T(\mathrm{~K})$ & $Z_{\text {Rot }}^{3 / 2}(T)$ & $Z_{\text {Rot }}^{1 / 2}(T)$ & $Z_{\text {Rot }}^{3 / 2}(T)+Z_{\text {Rot }}^{1 / 2}(T)$ & $Z_{\text {Vib }}(T)$ & $Z_{\text {Tot }}(T)$ & $Z_{\text {JPL }}(T)$ \\
\hline \multicolumn{7}{c}{${ }^{79} \mathrm{BrO}$} \\
150 & 1965.33 & 0.184 & 1965.51 & 1.001 & 1967.42 & 1949.83 \\
225 & 2941.8 & 6.074 & 2947.87 & 1.0099 & 2977.04 & 2932.18 \\
300 & 3918.94 & 38.03 & 3956.97 & 1.0321 & 4084.13 & 3941.17 \\
296 & 3866.81 & 35.24 & 3902.05 & 1.0306 & 4021.52 & \\
& & \multicolumn{7}{c}{${ }^{21} \mathrm{BrO}$} & & & \\
150 & 1973.40 & 0.184 & 1973.59 & 1.001 & 1975.50 & 1957.96 \\
225 & 2953.95 & 6.099 & 2960.05 & 1.0099 & 2989.33 & 2944.41 \\
300 & 3935.17 & 38.18 & 3973.35 & 1.0321 & 4101.03 & 3957.59 \\
296 & 3882.82 & 35.38 & 3918.20 & 1.0306 & 4038.17 & \\
\hline
\end{tabular}

$\gamma_{\text {air }}$ in $\mathrm{MHz} /$ torr at $296 \mathrm{~K}$

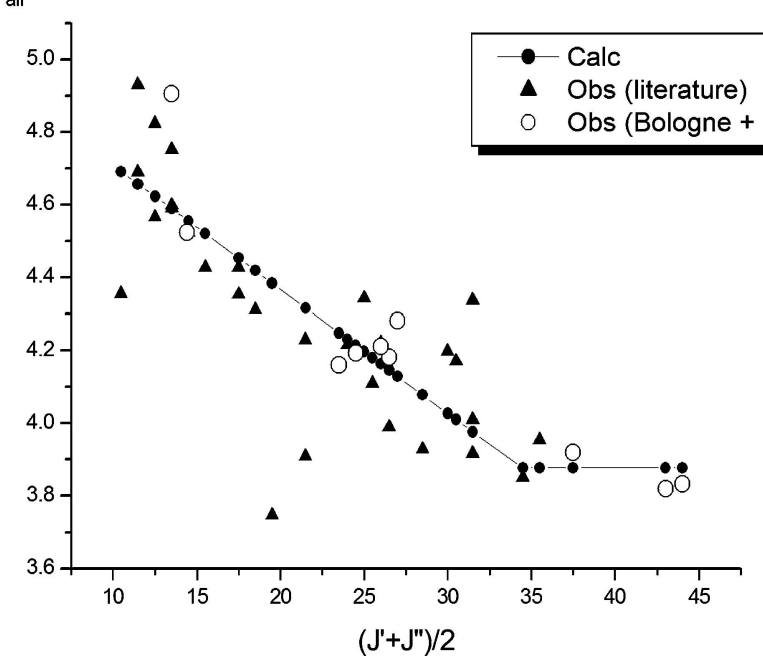

Figure 1. Air broadening parameter $\gamma_{\text {air }}$ for $\mathrm{HNO}_{3}$ as a function of $\left(J^{\prime}+J^{\prime \prime}\right) / 2$.

to generate the air broadening coefficients for the whole set of $\mathrm{HNO}_{3}$ lines, except for the lines for which these broadening coefficients were measured: in this case we used the measured data instead of the calculated ones.

For the temperature dependence exponent, the only existing data vary from 0.57 to 0.74 for $n_{\mathrm{N} 2}$ and 0.67 to 0.85 for $n_{\mathrm{O} 2}$ (Goyette et al., 1991, 1998), (Colmont et al., 2003). When looking in more details at these studies it was not possible to set up a reasonable empirical description for the rotational dependence of $n_{\mathrm{air}}$, and for this reason, the constant value $n_{\text {air }}=0.70$ was adopted for all the $\mathrm{HNO}_{3}$ lines in MASTER. 
Finally the value which is quoted for the self-broadening coefficient $\gamma_{\text {self }} \approx 31.8$ $\mathrm{MHz} / \mathrm{Torr}$ is an average of the values measured in $\mathrm{Zu}$ et al. (2002).

\subsubsection{Pressure Shifts}

Pressure shift measurements were performed in Bologna during this study for the $319.221,319.897,320.005,322.348$ and $344.241 \mathrm{GHz}$ lines of $\mathrm{HNO}_{3}$, leading to rather low values for the pressure shifts $\left(\delta_{\text {air }}=17(4),-32(6), 12(15), 22(2)\right.$ and $4(2) \mathrm{kHz} / T o r r$, respectively). In order to avoid systematic errors for the lines for which no information is available, it was decided to implement a zero value for all $\mathrm{HNO}_{3}$ pressure shifts in the MASTER database.

\subsection{HYDROGEN CHLORIDE (HCI): MOLECULE 15}

\subsubsection{Line Positions and Line Intensities}

For the hydrogen chloride molecule, it is necessary to take into account the hyperfine structure to get accurate line positions and line intensities in the microwave or submillimeter spectral region (Nolt et al., 1987; Klaus et al., 1998; Odashima et al., 1999; Cazzoli and Puzzarini, 2004 and references therein). Two sets of $\mathrm{HCl}$ rotational transitions (with a triplet hyperfine structure) are observable at 625.0 $\mathrm{GHz}$ and $625.9 \mathrm{GHz}$ within the channel F of MASTER: they correspond to the $J^{\prime}-$ $J^{\prime \prime}=1-0$ transitions of the $\mathrm{H}^{37} \mathrm{Cl}$ and $\mathrm{H}^{35} \mathrm{Cl}$ isotopic species of hydrogen chloride, respectively.

The line positions that we used for MASTER are the experimental positions measured by Klaus et al., (1998), which were confirmed by the very accurate measurements performed very recently by Cazzoli and Puzzarini (2004). These measurements are in excellent agreement with the line positions previously measured by Nolt et al. (1987).

The line intensities in the JPL, SAO and HITRAN databases were generated using the value of the $\mathrm{HCl}$ dipole moment measured by Stark effect (Kaiser, 1970; De DeLeeuw and Dymanus, 1973). On the other hand for both $\mathrm{H}^{35} \mathrm{Cl}$ and $\mathrm{H}^{37} \mathrm{Cl}$ the partition functions in HITRAN are smaller than those in the JPL catalog for the whole $70-300 \mathrm{~K}$ temperature range. For example at $300 \mathrm{~K}$ one has $Z_{\text {JPL }}(300 \mathrm{~K}) / Z_{\mathrm{HITRAN}}(300 \mathrm{~K}) \approx 1.024$, and for this reason, the intensities for $\mathrm{HCl}$ in the JPL catalog are $\approx 2 \%$ weaker than those in HITRAN. To resolve this discrepancy a new computation of the $\mathrm{HCl}$ partition function was performed during the present study which leads to an excellent agreement with the HITRAN values.

\subsubsection{Line Broadening and Line Shift Coefficients}

Drouin (2004a) measured the $\mathrm{N}_{2}$ - and $\mathrm{O}_{2}$-pressure broadenings and pressure shifts for the rotational $J=1 \leftarrow 0$ lines of $\mathrm{H}^{35} \mathrm{Cl}$ located near $625 \mathrm{GHz}$, respectively. 
The $\mathrm{N}_{2}$ - and $\mathrm{O}_{2}$-broadening coefficients were measured at different temperatures leading to the $n$-temperature dependences of these coefficients. Therefore the airbroadening coefficients $\gamma_{\text {air }}(296 \mathrm{~K})=3.420(7) \mathrm{MHz} /$ Torr and $n_{\text {air }}=0.73(3)$ issued from these results were implemented in the MASTER database for both $\mathrm{H}^{35} \mathrm{Cl}$ and $\mathrm{H}^{37} \mathrm{Cl}$. It has to be pointed out that the broadening coefficients achieved by Park et al. (1991) for the $J=4 \leftarrow 3$ of $\mathrm{H}^{35} \mathrm{Cl}$ located near $2.5 \mathrm{THz}$ are quite different from those obtained for the $625 \mathrm{GHz}$ lines, but this is not a surprise considering the strong dependence on the $m$ rotational number $(m=-J$ and $m=J+1$ for the P- and R-lines, respectively) which was noticed for the $1 \leftarrow 0$ fundamental band at 2,886 $\mathrm{cm}^{-1}$ (Houdeau et al., 1980; Pine and Fried, 1985; Pine and Looney, 1987; Ballard et al., 1985; Chackerian et al., 1985).

From the various existing self-broadening measurements (Pourcin 1972; Pourcin et al., 1981), one can estimate that the HITRAN value $\gamma_{\text {self }}(296 \mathrm{~K}) \approx 8.61$ $\mathrm{MHz} /$ Torr is reasonable. Finally the value of the air-pressure shift $\delta_{\text {air }}(296 \mathrm{~K})=$ 0.146(3) MHz/Torr obtained by Drouin (2004a) was also implemented in MASTER.

\subsection{CHLORIDE MONOXIDE (ClO): MOLECULE 18}

Numerous line position studies were performed recently in the infrared or microwave spectral regions (Cohen et al., 1984; Rinsland et al., 1992; Burkholder et al., 1987; Drouin et al., 2001b). The ClO linelist which is present in the JPL database was generated in 1991, using extensive and accurate measurements (Cohen et al., 1984). The excellent quality of the line positions was confirmed by recent measurements (Drouin et al., 2001b). The line intensities were computed using the $\mathrm{ClO}$ measured dipole moment (Yaron et al., 1988). The partition function given in the JPL catalog, in HITRAN and calculated in the present study are in excellent agreement. Therefore, because of their excellent quality, the line positions and intensities quoted in the JPL catalog were implemented in the MASTER database.

For the air-broadening coefficients and their temperature dependences, we used the values which were measured at DLR (Bauer et al., 1998a) for the $501.2 \mathrm{GHz}$ lines $\left(J^{\prime}=13.5 \leftarrow J^{\prime \prime}=12.5\right.$ transition of $\left.{ }^{35} \mathrm{ClO}\right)$, namely $\gamma_{\text {air }}=3.23(13) \mathrm{MHz} /$ Torr $@ 296 \mathrm{~K}$ and $n_{\text {air }}=0.69(6)$. However, it has to be pointed out that these broadening coefficients are significantly higher than for the $204.4\left(J^{\prime}=5.5 \leftarrow J^{\prime \prime}=4.5\right.$ of $\left.{ }^{35} \mathrm{ClO}\right)$ and $649.4 \mathrm{GHz}$ lines $\left(J^{\prime}=13.5 \leftarrow J^{\prime \prime}=12.5\right.$ of $\left.{ }^{35} \mathrm{ClO}\right)$ for which the values $\gamma_{\text {air }}=2.54(8) \mathrm{MHz} /$ Torr $@ 296 \mathrm{~K}$ (with $n_{\text {air }}=0.62(6)$ ) and $\gamma_{\text {air }}=2.11(6)$ MHz/Torr @ $296 \mathrm{~K}$ (with $n_{\text {air }}=0.85(9)$ ) respectively were obtained at JPL by Oh and Cohen (1994). Therefore, further air broadening measurements should be performed for $\mathrm{ClO}$ in order to validate more accurately the quality of the airbroadening coefficients. 


\subsection{METHYL CHLORIDE $\left(\mathrm{CH}_{3} \mathrm{Cl}\right)$ : MOLECULE 24}

\subsubsection{Line Positions and Intensities}

Numerous microwave measurements were performed for both the $\mathrm{CH}_{3}^{35} \mathrm{Cl}$ and $\mathrm{CH}_{3}^{37} \mathrm{Cl}$ isotopic species, and these results were completed by analyses performed in the $v_{3}$ and $v_{6}$ band (Wlodarczak et al., 1985a, 1985b, 1986; Carpenter and Seo, 1985; Demaison et al., 1994). Therefore, the accurate line positions present in the JPL catalog were included in the MASTER database.

The JPL catalog uses, for the line intensity calculation, the value of the permanent dipole moment of $\mathrm{CH}_{3} \mathrm{Cl}$ determined by laser-Stark spectroscopy (Wlodarczak et al., 1985b). On the other hand, the partition function used in the JPL catalog for $\mathrm{CH}_{3} \mathrm{Cl}$ accounts only for its spin-rotational contribution and since $Z_{\mathrm{Vib}}(300 \mathrm{~K})=$ 1.050 the intensities are overestimated by $5 \%$. Consequently the line intensities present in the JPL catalog for $\mathrm{CH}_{3} \mathrm{Cl}$ were divided by $\mathrm{Z}_{\mathrm{Vib}}(300 \mathrm{~K})=1.050$ before their introduction in the MASTER database.

\subsubsection{Line Broadening Coefficients}

Numerous recent analyses were performed in the infrared region (Blanquet $e t$ al., 1993a, 1993b; Bouanich et al., 2001). The $\mathrm{N}_{2}$ - and $\mathrm{O}_{2}$-broadening coefficients were measured at room temperature in the $v_{3}$ band. Also theoretical calculations of these broadening coefficients were performed (Bouanich et al., 1993). In both cases (theory and experiment) a variation with the $J$ and $K$ quantum numbers was pointed out. More precisely, the $\mathrm{N}_{2}$-broadening coefficients (resp. the $\mathrm{O}_{2}$-ones) vary from $\gamma_{\mathrm{N} 2} \approx 4.7 \mathrm{MHz} /$ Torr for $J=3$ to $\gamma_{\mathrm{N} 2} \approx 3.9 \mathrm{MHz} /$ Torr for $J=46$ (resp. $\gamma_{\mathrm{O} 2} \approx 3.7 \mathrm{MHz} /$ Torr for $J=3$ to $\gamma_{\mathrm{O} 2} \approx 2.9 \mathrm{MHz} /$ Torr for $J=46$ ). More recently, the temperature dependence of the $\mathrm{N}_{2}$-broadening coefficient was measured and in this case also a $J$-dependence was pointed out (Bakri et al., 2002). According to these results a mean value for the air broadening can be estimated $\left(\gamma_{\text {air }}=0.79 \gamma_{\mathrm{N} 2}+0.21 \gamma_{\mathrm{O} 2}\right)$ leading the values $\gamma_{\text {air }} \approx 4.04 \mathrm{MHz} /$ Torr and $n_{\text {air }}=0.7$ which were implemented in the MASTER database. Finally $\gamma_{\text {self }} \approx 20 \mathrm{MHz} /$ Torr was used for the self-broadening parameter (Harde et al., 1994, 1997a, 1997b).

\subsection{BROMIDE MONOXIDE (BrO): MOLECULE 40}

As it is the case for other halogen monoxides, $\mathrm{BrO}$ has a single vacancy in the $\mathrm{p} \pi$ antibonding orbital. This gives rise to an inverted doublet $\Pi$ ground electronic state. More explicitly the $X_{1}^{2} \Pi_{1 / 2}$ (with $J \geq 1 / 2$ ) doublet component is located at $\sim 970 \mathrm{~cm}^{-1}$ above the lower $X_{1}^{2} \Pi_{3 / 2}$ (with $J \geq 3 / 2$ ) component. The vibrational frequencies are $\omega_{0}=723.41420 \mathrm{~cm}^{-1}$ and $\omega_{0}=721.92715 \mathrm{~cm}^{-1}$ for the ${ }^{79} \mathrm{BrO}$ and ${ }^{81} \mathrm{BrO}$ species, respectively. To reproduce the rotational energy levels, one has to account for the various hyperfine effects, and since the nuclear spin of ${ }^{79} \mathrm{Br}$ and ${ }^{81} \mathrm{Br}$ is equal to $I=3 / 2$, each rotational component (with a given $J$ value) is split 
in general into four $F$ components corresponding to $|F-J|=3 / 2$ or $1 / 2$. Also it is necessary to account for the $\Lambda$ doubling (Amano et al., 1972; Brown et al., 1972; Butler et al., 1984; Cohen et al., 1981; Drouin et al., 2001a). For the MASTER database we used the line positions and line intensities quoted in the JPL catalog (Cohen et al., 1981).

As $\mathrm{BrO}$ is missing in HITRAN, we have generated the partition functions for ${ }^{79} \mathrm{BrO}$ and ${ }^{81} \mathrm{BrO}$, using:

$$
Z_{\mathrm{Tot}}(T)=Z_{\mathrm{Vib}}(T)\left[Z_{\mathrm{Rot}}^{3 / 2}(T)+Z_{\mathrm{Rot}}^{1 / 2}(T)\right]
$$

where $Z_{\mathrm{Vib}}(T)$ is the vibrational partition function and $Z_{\mathrm{Rot}}^{3 / 2}(T)$ and $Z_{\mathrm{Rot}}^{1 / 2}(T)$ are the individual contributions of the rotational partition function for the $X^{2} \Pi_{3 / 2}$ and $\mathrm{X}^{2} \Pi_{1 / 2}$ spin components respectively.

One has:

$$
\begin{aligned}
& Z_{\mathrm{Rot}}^{3 / 2}(T)=\sum_{J \geq 3 / 2} \sum_{F} \sum_{ \pm}(2 F+1) \exp \left(-E_{J, F, \pm}^{3 / 2, \mathrm{Rot}} / k T\right) \\
& Z_{\mathrm{Rot}}^{1 / 2}(T)=\sum_{J \geq 1 / 2} \sum_{F} \sum_{ \pm}(2 F+1) \exp \left(-E_{J, F, \pm}^{1 / 2, \mathrm{Rot}} / k T\right)
\end{aligned}
$$

In Equations (10) and (11) the summation is performed starting from $J \geq 3 / 2$ and $J \geq 1 / 2$ for $Z_{\mathrm{Rot}}^{3 / 2}(T)$ and $Z_{\mathrm{Rot}}^{1 / 2}(T)$, respectively, for $F$ such as $|F-J|=3 / 2$ or $1 / 2$, and for each of the two \pm lambda subcomponents. Actually it proved that the convergence of the summation is obtained at $J \approx 85$ for temperatures up to $T=330 \mathrm{~K} .{ }^{4}$ From the comparison which is performed in Table VIII, it appears that the partition functions calculated in the present study are systematically larger than the JPL ones. The source of this disagreement which occurs for all temperatures is not clear.

The JPL partition functions were used to generate the $\mathrm{BrO}$ intensities present in the JPL catalog which were introduced in the MASTER database. Therefore, provided that the present results on the $\mathrm{BrO}$ partition function are confirmed by further studies, the $\mathrm{BrO}$ intensities may be overestimated by $\approx 3.6 \%$ at $300 \mathrm{~K}$ and by $\approx 1 \%$ at $150 \mathrm{~K}$ (Table VIII).

For the air-broadening coefficients we used the values $\gamma_{\text {air }}(296 \mathrm{~K})=3.54(3)$ $\mathrm{MHz} /$ Torr and $n_{\text {air }}=0.45(18)$ as measured at DLR (Bauer et al., 1998a) for the $499.6 \mathrm{GHz}$ line of ${ }^{79} \mathrm{BrO}(J=19.5 \leftarrow 18.5$ transition $)$. After the generation of the MASTER database, new $\mathrm{N}_{2}$ - and $\mathrm{O}_{2}$-broadening measurements were performed simultaneously at Ibaraki University and at the Jet Propulsion laboratory (Yamada et al., 2003) for the 624.768 and $650.178 \mathrm{GHz}$ lines (the $J=24.5 \leftarrow 23.5$ and $J=$ $25.5 \leftarrow 24.5$ rotational transitions in the $\mathrm{X}^{2} \Pi_{3 / 2}$ vibronic state of ${ }^{81} \mathrm{BrO}$ ), leading to rather reasonable agreements for the broadening parameters measured in both laboratories. From these new measurements and using $\gamma_{\text {air }}=0.79 \gamma_{\mathrm{N}_{2}}+0.21 \gamma_{\mathrm{O}_{2}}$ the air-broadening coefficients are $\gamma_{\text {air }}=3.05(5) \mathrm{MHz} / \mathrm{Torr}, n_{\text {air }}=0.80(5)$, and $\gamma_{\text {air }}=3.03(7) \mathrm{MHz} /$ Torr, $n_{\text {air }}=0.81(7)$ for the 624.768 and $650.178 \mathrm{GHz}$ lines, 
respectively. These values are significantly weaker than those measured earlier at DLR for the $J=19.5 \leftarrow 18.5$ transition of ${ }^{79} \mathrm{BrO}$, indicating a very likely decreasing with $\mathrm{J}$ of the air-broadening parameters. This $J$-dependence should be investigated in more details by further air broadening measurements.

\section{The "Possible Interfering Species" in the MASTER Database}

The following molecules were added in the linelist as possible interfering species for the target molecules of MASTER.

\subsection{SULFUR DIOXIDE ( $\mathrm{SO}_{2}$ : MOLECULE 9), AND NITROGEN DIOXIDE $\left(\mathrm{NO}_{2}\right.$ : MOLECULE 10)}

For ${ }^{14} \mathrm{~N}^{16} \mathrm{O}_{2}$ we used the line positions and intensities that were generated by Perrin et al. $(1988,1992,1998$ a) for HITRAN: these parameters account for the hyperfine structure and for the electron spin-rotation interaction. The partition function which was used to calculate the line intensities accounts for the spin-rotation and vibrational contributions. Therefore these data which involve both the ground and the first vibrational states are more complete that those available in the JPL catalog.

For ${ }^{32} \mathrm{~S}^{16} \mathrm{O}_{2},{ }^{34} \mathrm{~S}^{16} \mathrm{O}_{2},{ }^{32} \mathrm{~S}^{16} \mathrm{O}^{18} \mathrm{O}$, and ${ }^{33} \mathrm{~S}^{16} \mathrm{O}_{2}$, the line positions quoted in the JPL catalog are of excellent quality owing to the numerous studies performed for this molecule (Lovas, 1985, 2004). On the other hand, before their implementation in the MASTER database, the line intensities present in the JPL catalog were divided by a factor equal to the vibrational partition function $Z_{\mathrm{Vib}}(300 \mathrm{~K})=1.0965$, since $Z_{\mathrm{Vib}}$ was not considered in the JPL calculations.

For the air- and self-broadening coefficients, we used the values which were included in the 1998 version of HITRAN (Perrin et al., 1998a) $\gamma_{\text {air }}=4.73 \mathrm{MHz} /$ Torr, $\gamma_{\text {self }}=15.8 \mathrm{MHz} /$ Torr for $\mathrm{SO}_{2}$, and $\gamma_{\text {air }}=2.64 \mathrm{MHz} /$ Torr for $\mathrm{NO}_{2}$. For $\mathrm{NO}_{2}$ this value is however lower than values measured by Goyette et al. (1988b), $\gamma_{\text {air }}=3.14(3) \mathrm{MHz} /$ Torr and $\gamma_{\text {air }}=3.00(5) \mathrm{MHz} /$ Torr for the $231.2 \mathrm{GHz}$ and 247.4 $\mathrm{GHz}$ lines, respectively. Therefore an update for $\mathrm{NO}_{2}$ may have to be performed provided that these results are completed by a more extended set of broadening coefficients. Actually according to recent infrared measurements (Benner et al., 2004) the rotational dependence for these broadening coefficients is far from being negligible. Finally, for $\mathrm{NO}_{2}$, we used $\gamma_{\text {self }}=1.42 \mathrm{MHz} /$ Torr as it was calculated by Tejwani (1972).

\subsection{CARBONYL SULFIDE (OCS: MOLECULE 19)}

For OCS, the line positions and intensities quoted in the HITRAN are those given in the JPL catalog (Lovas, 1978). This means that the line intensities in both databases are overestimated by $\sim 20 \%$ because as already said the partition function used in the JPL catalog does not account for the vibrational contribution which at $300 \mathrm{~K}$ is 
$Z_{\mathrm{Vib}}(300 \mathrm{~K})=1.207$. For this reason all the OCS intensities were divided by this 1.207 factor before their introduction in the MASTER database.

For the air-broadening and the self-broadening coefficients we used the values $\gamma_{\text {air }}=3.57 \mathrm{MHz} /$ Torr and $\gamma_{\text {self }}=5.9 \mathrm{MHz} /$ Torr which were deduced from the measurements performed by Bouanich et al. (1987) and Depannemaecker and Lemaire (1988), respectively.

\subsection{FORMALDEHYDE $\left(\mathrm{H}_{2} \mathrm{CO}\right.$ : MOLECULE 20$)$}

The JPL line positions are of good quality (Bocquet et al., 1996 and references therein). As far as the intensities are concerned, the JPL calculation was performed using the $\mathrm{H}_{2} \mathrm{CO}$ dipole moment from (Fabricant et al., 1977 and references therein). Again, the vibrational partition function was neglected, but for $\mathrm{H}_{2} \mathrm{CO}$ this contribution is still negligible at $300 \mathrm{~K}$ (less than $5 \%$ ). Therefore the line positions and intensities present in the JPL catalog for the $\mathrm{H}_{2} \mathrm{CO}$ were implemented in the MASTER database.

For the air-broadening coefficients, the value $\gamma_{\text {air }}=4.70 \mathrm{MHz} /$ Torr which is issued from the existing air broadening measurements (Nadler et al., 1987) is used in the MASTER database. This value differs slightly from the value $\gamma_{\text {air }}=$ 4.22 MHz/Torr presently given in HITRAN (Rothman et al., 1998) and for which there is no information. For the self-broadening halfwidth, we used the measured $\gamma_{\text {self }}=23 \mathrm{MHz} /$ Torr (Nerf, 1975a). No value was found in the literature for the $n$ temperature dependence of the pressure linewidths which was set to $n=0.7$. Let us notice that the rotational dependence of these broadening coefficients is presumably rather large as pointed out by the calculation (Tejwani and Yeung, 1977) and the measurements (Nerf, 1975a).

\subsection{HYPOCHLOROUS ACID, HYPOBROMOUS ACID (HOCl AND HOBr: MOLECULES 21 AND 37)}

The $\mathrm{HOCl}$ and $\mathrm{HOBr}$ molecules are non-linear molecules of $C_{\mathrm{s}}$ symmetry and therefore both A- and B-type transitions with $\left(\Delta K_{\mathrm{a}}=\right.$ even and $\Delta K_{\mathrm{c}}=$ odd $)$ and ( $\Delta K_{\mathrm{a}}=$ odd and $\Delta K_{\mathrm{c}}=$ odd) selection rules, are observable in the microwave, submillimeter or far infrared regions for these two molecules (Singbeil et al., 1984; Gillis et al., 1984; Koga et al., 1989; Flaud et al., 1998b). HOCl and HOBr lines exhibit a hyperfine structure which is non negligible for the low rotational quantum numbers. This hyperfine structure is explicitly taken into account in the JPL database. On the other hand in HITRAN the hyperfine structure of $\mathrm{HOCl}$ was ignored and no parameters are available for $\mathrm{HOBr}$ in the millimeter region.

For $\mathrm{HOCl}$ and $\mathrm{HOBr}$ the line intensities given in the JPL catalog were generated using the parameters obtained by Singbeil et al. (1984) and Yoga et al. (1989) and a partition function which accounts only for the spin and rotational contributions. Therefore the intensities are (weakly) overestimated by a factor equal to the 
vibrational contribution at $300 \mathrm{~K}$ to the partition function $\left({ }^{\mathrm{HOCI}} Z_{\mathrm{Vib}}(300 \mathrm{~K})=1.035\right.$ and $\left.{ }^{\mathrm{HOBr}} Z_{\mathrm{Vib}}(300 \mathrm{~K})=1.058\right)$. As far as $\mathrm{HOCl}$ is concerned, this was also evidenced during the line intensity calculation performed for the far infrared region (Flaud et al., 1998b). Since these intensity corrections are rather weak the line positions and line intensities given in the JPL database were implemented in the MASTER database.

The air broadening coefficients and its $n$-temperature dependence which are quoted in HITRAN for HOCl, (namely: $\gamma_{\text {air }}=2.37 \mathrm{MHz} /$ Torr (at $296 \mathrm{~K}$ ) and $n_{\text {air }}=0.5$ ) are the original default values which were quoted for all molecules in the first version of the AFGL-HITRAN database and therefore have no real physical meaning. Therefore, we have followed the recommendations for the MIPAS (Flaud et al., 2003b) database and have implemented for $\mathrm{HOCl}$ the value $\gamma_{\text {air }}=3.94$ $\mathrm{MHz} /$ Torr (at $296 \mathrm{~K}$ ) which is the average values of two lines measured recently in the $v_{2}$ band (Shorter et al., 1997). Also the temperature dependence coefficient has been set to 0.7 , a value which seems more reasonable for this molecule than the value 0.5 quoted in the HITRAN database. These values were also used for $\mathrm{HOBr}$ which is rather similar to $\mathrm{HOCl}$.

\subsection{HYDROGEN CYANIDE (HCN: MOLECULE 23)}

For the line positions and line intensities, we used the parameters quoted in the HITRAN database. In fact the line intensities in the HITRAN database are 7\% weaker than those quoted in the JPL catalog. This is consistent with the fact that the vibrational contribution of the partition $\left(Z_{\mathrm{Vib}}(300 \mathrm{~K})=1.0725\right)$ is not considered during the JPL line intensity calculation leading to intensities overestimated by this factor.

Also the air-broadening coefficients that we used are the HITRAN values: these values were deduced from the results of Lemaire et al. (1996). Finally the self broadening $\gamma_{\text {self }} \approx 24 \mathrm{MHz} /$ Torr was measured by Nerf and Sonnenberg (1975b).

\subsection{HYDROXYL PEROXIDE $\left(\mathrm{H}_{2} \mathrm{O}_{2}\right.$ : MOLECULE 25)}

For the line positions and intensities we used the parameters that were generated by Perrin et al. (1996). In this calculation, the large amplitude $\mathrm{OH}$ torsional mode was accounted for both for the line positions and line intensities, leading to parameters more complete and accurate that those available in the JPL catalog or in HITRAN. For the air broadening halfwidth, we used the value $\gamma_{\text {air }}=3.94 \mathrm{MHz} /$ Torr which is an average value deduced from the measurements of Malathy Devi et al. (1986). This air broadening halfwidth is more or less in agreement with the results given by Goyette et al. (1988b): $\gamma_{\text {air }}=4.45(12) \mathrm{MHz} /$ Torr and $\gamma_{\text {air }}=3.92(7) \mathrm{MHz} /$ Torr for the 223.1 and $229.8 \mathrm{GHz}$ lines, respectively. 


\subsection{CARBONYL FLUORIDE ( $\mathrm{COF}_{2}$ : MOLECULE 29)}

The JPL line positions which were generated using the spectroscopic constants given by Carpenter (1974) and Cohen and Lewis-Bevin (1991) were introduced in the MASTER database. The JPL line intensities were generated using the $\mathrm{COF}_{2}$ permanent dipole moment measured by Laurie and Pence (1962) and a partition function which accounts only for the rotational contribution, leading to intensities overestimated by a factor equal to $Z_{\mathrm{Vib}}(300 \mathrm{~K})=1.166$ : these line intensities were introduced in the MASTER database after a division by this factor.

According to the recommendations of Rinsland et al. (1992) we used, for the airbroadening, the self-broadening coefficients and their $n$-temperature dependence, the values $\gamma_{\text {air }}=3.33 \mathrm{MHz} /$ Torr $\gamma_{\text {self }}=6.90 \mathrm{MHz} /$ Torr and $n=0.94$ (at $T=296$ K) achieved by May (1992).

\subsection{HYDROPEROXYL RADICAL ( $\mathrm{HO}_{2}$ : MOLECULE 33)}

For the line positions and intensities we used the parameters quoted in the JPL database. For the air broadening coefficients, the values obtained recently in the microwave (Chance et al., 1994b) and in the infrared region (Nelson and Zahniser, 1994) differ by about $30 \%$. We decided to include in the database the microwave value 5.6 MHz/Torr (Chance et al., 1994a) which is likely more accurate than the infrared one (Nelson and Zahniser, 1994).

\section{Conclusion}

This paper describes the MASTER database. The spectral line parameters (line positions, line intensities and line broadening coefficients) were derived, depending of their estimated accuracy, (i) by combining parameters coming from the JPL and HITRAN catalogs (ii) from data taken into the literature or (iii) using experimental data and theoretical results obtained within this study. The line positions available in the JPL catalog or in the literature are almost always adequate for the MASTER retrievals. For some of the species under study the line intensities had to be recomputed since they are incorrect for atmospheric applications in the usual public access databases. Finally, as expected, the existing air-broadening coefficients $\gamma_{\text {air }}$ and $n_{\text {air }}$ were not always at the required accuracy in the literature and for this reason, measurements had to be performed at Bologna, Lille and Wessling (Bauer et al., 1998a; Demaison et al., 2004). Since the $\mathrm{HNO}_{3}$ linelist for MASTER includes numerous transitions which involve an extended set of rotational transitions an empirical model was designed down to characterize the rotational dependence of the air-broadening coefficients for this molecule. Finally it is clear that the data on air line shifts are still rather sparse in the literature but that its effect is likely to be negligible in the investigated frequency range for most of the molecules studied here. 


\section{Acknowledgments}

The European Space Agency (ESA) is gratefully acknowledged for its financial assistance under the ESTEC contract ITT RfQ AO/1-4143/02/NF/FF. PhLAM (Lille) and LPPM (Orsay) thanks the "Laboratoire Européen Associé" HiRes for financial support. Part of this work was also founded by the bilateral exchange program GALILEO between Lille and Bologna.

\section{Appendix: Partition Function for ${ }^{79} \mathrm{BrO}$ and ${ }^{81} \mathrm{BrO}$ in the $150-320 \mathrm{~K}$ Temperature Range}

As for other halogen monoxides, $\mathrm{BrO}$ has a single vacancy in the $\mathrm{p} \pi$ anti-bounding orbital. This gives rise to an inverted doublet $\Pi$ ground electronic state. More explicitly the $X_{1}^{2} \Pi_{1 / 2}$ (with $J \geq 1 / 2$ ) doublet component is located at $\sim 970 \mathrm{~cm}^{-1}$ above the lower $X_{1}^{2} \Pi_{3 / 2}$ (with $J \geq 3 / 2$ ) component. The vibrational frequencies are $\omega_{0}=723.41420 \mathrm{~cm}^{-1}$ and $\omega_{0}=721.92715 \mathrm{~cm}^{-1}$ for the ${ }^{79} \mathrm{BrO}$ and ${ }^{81} \mathrm{BrO}$ species, respectively.

Therefore, for $\mathrm{BrO}$ the partition function takes the general form

$$
Z_{\mathrm{Tot}}(T)=Z_{\mathrm{Vib}}(T)\left[Z_{\mathrm{Rot}}^{3 / 2}(T)+Z_{\mathrm{Rot}}^{1 / 2}(T)\right]
$$

where $Z_{\mathrm{Vib}}(T)$ is the vibrational partition function (see Equation (2)), and $Z_{\mathrm{Rot}}^{3 / 2}(T)$ and $Z_{\mathrm{Rot}}^{1 / 2}(T)$ are the individual contribution of the rotational partition function for the ${ }^{2} \Pi_{3 / 2}$ and ${ }^{2} \Pi_{1 / 2}$ spin components respectively.

To reproduce the rotational energy levels, one has to account for the various hyperfine effects. More explicitly, because the nuclear spin of ${ }^{79} \mathrm{Br}$ and ${ }^{81} \mathrm{Br}$ is equal to $I=3 / 2$, each rotational component (with a given $J$ value) is split in general into four $F$ components corresponding to $|F-J|=3 / 2$ or $1 / 2$. Also it is necessary to account for the $\Lambda$ doubling which is quoted either by the " \pm " in Equations (A.2) and (A.3).

One has

$$
\begin{aligned}
& Z_{\mathrm{Rot}}^{3 / 2}(T)=\sum_{J \geq 3 / 2} \sum_{F} \sum_{ \pm}(2 F+1) \exp \left(-E_{J, F, \pm}^{3 / 2, \mathrm{Rot}} / k T\right) \\
& Z_{\mathrm{Rot}}^{1 / 2}(T)=\sum_{J \geq 1 / 2} \sum_{F} \sum_{ \pm}(2 F+1) \exp \left(-E_{J, F, \pm}^{1 / 2, \mathrm{Rot}} / k T\right)
\end{aligned}
$$

In Equations (A.1) and (A.2) the summation is performed starting from $J \geq 3 / 2$ and $J \geq 1 / 2$ for $Z_{\mathrm{Rot}}^{3 / 2}(T)$ and $Z_{\mathrm{Rot}}^{1 / 2}(T)$, respectively, up to maximum $J$ values of $J_{\text {Max }}=85.5$ and $J_{\text {Max }}=65.5$ for the $X_{1}^{2} \Pi_{3 / 2}$ and $X_{1}^{2} \Pi_{1 / 2}$ system, respectively (since preliminary tests have shown that the convergence of the summation was already achieved). This calculation was performed using the rotational levels for $\mathrm{X}_{1}^{2} \Pi_{3 / 2}$ and $\mathrm{X}_{1}^{2} \Pi_{1 / 2}$ which are quoted in the JPL catalog. The results of the calculations are presented in Tables (A.I) and (A.II) for the ${ }^{79} \mathrm{BrO}$ and ${ }^{81} \mathrm{BrO}$ isotopic 
Table A.I. Partition function for ${ }^{79} \mathrm{BrO}$

\begin{tabular}{|c|c|c|c|c|c|c|c|c|c|}
\hline$T(K)$ & $Z_{\mathrm{Rot}}^{3 / 2}(T)$ & $Z_{\mathrm{Rot}}^{1 / 2}(T)$ & $Z_{\mathrm{Vib}}(T)$ & $Z_{\text {Tot }}(T)$ & $T(K)$ & $Z_{\mathrm{Rot}}^{3 / 2}(T)$ & $Z_{\mathrm{Rot}}^{1 / 2}(T)$ & $Z_{\mathrm{Vib}}(T)$ & $Z_{\mathrm{Tot}}(T)$ \\
\hline 150 & 1965.33 & 0.184 & 1.001 & 1967.42 & 236 & 3085.08 & 8.501 & 1.0123 & 3131.63 \\
\hline 151 & 1978.34 & 0.197 & 1.001 & 1980.55 & 237 & 3098.1 & 8.752 & 1.0125 & 3145.8 \\
\hline 152 & 1991.36 & 0.21 & 1.0011 & 1993.69 & 238 & 3111.13 & 9.008 & 1.0128 & 3159.98 \\
\hline 153 & 2004.38 & 0.225 & 1.0011 & 2006.83 & 239 & 3124.15 & 9.27 & 1.013 & 3174.19 \\
\hline 154 & 2017.39 & 0.24 & 1.0012 & 2019.98 & 240 & 3137.18 & 9.538 & 1.0133 & 3188.42 \\
\hline 155 & 2030.41 & 0.256 & 1.0012 & 2033.13 & 241 & 3150.21 & 9.811 & 1.0135 & 3202.66 \\
\hline 156 & 2043.42 & 0.273 & 1.0013 & 2046.29 & 242 & 3163.23 & 10.089 & 1.0137 & 3216.93 \\
\hline 157 & 2056.44 & 0.291 & 1.0013 & 2059.45 & 243 & 3176.26 & 10.374 & 1.014 & 3231.21 \\
\hline 158 & 2069.45 & 0.31 & 1.0014 & 2072.62 & 244 & 3189.28 & 10.664 & 1.0142 & 3245.52 \\
\hline 159 & 2082.47 & 0.329 & 1.0014 & 2085.79 & 245 & 3202.31 & 10.96 & 1.0145 & 3259.85 \\
\hline 160 & 2095.49 & 0.35 & 1.0015 & 2098.98 & 246 & 3215.34 & 11.261 & 1.0148 & 3274.2 \\
\hline 161 & 2108.5 & 0.372 & 1.0016 & 2112.16 & 247 & 3228.36 & 11.569 & 1.015 & 3288.57 \\
\hline 162 & 2121.52 & 0.395 & 1.0016 & 2125.36 & 248 & 3241.39 & 11.883 & 1.0153 & 3302.96 \\
\hline 163 & 2134.54 & 0.418 & 1.0017 & 2138.56 & 249 & 3254.42 & 12.203 & 1.0155 & 3317.37 \\
\hline 164 & 2147.55 & 0.444 & 1.0018 & 2151.77 & 250 & 3267.44 & 12.529 & 1.0158 & 3331.8 \\
\hline 165 & 2160.57 & 0.47 & 1.0018 & 2164.98 & 251 & 3280.47 & 12.861 & 1.0161 & 3346.26 \\
\hline 166 & 2173.59 & 0.497 & 1.0019 & 2178.21 & 252 & 3293.5 & 13.2 & 1.0163 & 3360.73 \\
\hline 167 & 2186.6 & 0.526 & 1.002 & 2191.44 & 253 & 3306.53 & 13.545 & 1.0166 & 3375.23 \\
\hline 168 & 2199.62 & 0.556 & 1.002 & 2204.67 & 254 & 3319.55 & 13.896 & 1.0169 & 3389.75 \\
\hline 169 & 2212.64 & 0.588 & 1.0021 & 2217.92 & 255 & 3332.58 & 14.254 & 1.0172 & 3404.29 \\
\hline 170 & 2225.66 & 0.62 & 1.0022 & 2231.17 & 256 & 3345.61 & 14.618 & 1.0174 & 3418.86 \\
\hline 171 & 2238.67 & 0.655 & 1.0023 & 2244.43 & 257 & 3358.64 & 14.989 & 1.0177 & 3433.45 \\
\hline 172 & 2251.69 & 0.69 & 1.0024 & 2257.7 & 258 & 3371.66 & 15.366 & 1.018 & 3448.06 \\
\hline 173 & 2264.71 & 0.728 & 1.0024 & 2270.97 & 259 & 3384.69 & 15.751 & 1.0183 & 3462.69 \\
\hline 174 & 2277.73 & 0.766 & 1.0025 & 2284.26 & 260 & 3397.72 & 16.142 & 1.0186 & 3477.35 \\
\hline 175 & 2290.75 & 0.807 & 1.0026 & 2297.55 & 261 & 3410.75 & 16.54 & 1.0189 & 3492.03 \\
\hline 176 & 2303.76 & 0.849 & 1.0027 & 2310.86 & 262 & 3423.78 & 16.944 & 1.0192 & 3506.73 \\
\hline 177 & 2316.78 & 0.893 & 1.0028 & 2324.17 & 263 & 3436.81 & 17.356 & 1.0195 & 3521.46 \\
\hline 178 & 2329.8 & 0.938 & 1.0029 & 2337.49 & 264 & 3449.84 & 17.775 & 1.0198 & 3536.21 \\
\hline 179 & 2342.82 & 0.986 & 1.003 & 2350.82 & 265 & 3462.86 & 18.201 & 1.0201 & 3550.98 \\
\hline 180 & 2355.84 & 1.035 & 1.0031 & 2364.16 & 266 & 3475.89 & 18.634 & 1.0204 & 3565.78 \\
\hline 181 & 2368.86 & 1.086 & 1.0032 & 2377.51 & 267 & 3488.92 & 19.074 & 1.0207 & 3580.6 \\
\hline 182 & 2381.88 & 1.139 & 1.0033 & 2390.87 & 268 & 3501.95 & 19.522 & 1.021 & 3595.45 \\
\hline 183 & 2394.9 & 1.195 & 1.0034 & 2404.23 & 269 & 3514.98 & 19.976 & 1.0213 & 3610.32 \\
\hline 184 & 2407.91 & 1.252 & 1.0035 & 2417.61 & 270 & 3528.01 & 20.439 & 1.0216 & 3625.21 \\
\hline 185 & 2420.93 & 1.311 & 1.0036 & 2431 & 271 & 3541.04 & 20.908 & 1.0219 & 3640.13 \\
\hline 186 & 2433.95 & 1.373 & 1.0037 & 2444.4 & 272 & 3554.07 & 21.385 & 1.0223 & 3655.07 \\
\hline 187 & 2446.97 & 1.436 & 1.0038 & 2457.81 & 273 & 3567.1 & 21.87 & 1.0226 & 3670.04 \\
\hline 188 & 2459.99 & 1.502 & 1.004 & 2471.23 & 274 & 3580.13 & 22.363 & 1.0229 & 3685.04 \\
\hline 189 & 2473.01 & 1.571 & 1.0041 & 2484.67 & 275 & 3593.16 & 22.863 & 1.0232 & 3700.06 \\
\hline 190 & 2486.03 & 1.641 & 1.0042 & 2498.11 & 276 & 3606.19 & 23.371 & 1.0236 & 3715.1 \\
\hline 191 & 2499.05 & 1.714 & 1.0043 & 2511.56 & 277 & 3619.22 & 23.886 & 1.0239 & 3730.17 \\
\hline
\end{tabular}


Table A.1. (Continued)

\begin{tabular}{|c|c|c|c|c|c|c|c|c|c|}
\hline$T(K)$ & $Z_{\mathrm{Rot}}^{3 / 2}(T)$ & $Z_{\mathrm{Rot}}^{1 / 2}(T)$ & $Z_{\mathrm{Vib}}(T)$ & $Z_{\mathrm{Tot}}(T)$ & $T(K)$ & $Z_{\mathrm{Rot}}^{3 / 2}(T)$ & $Z_{\mathrm{Rot}}^{1 / 2}(T)$ & $Z_{\mathrm{Vib}}(T)$ & $Z_{\text {Tot }}(T)$ \\
\hline 192 & 2512.07 & 1.79 & 1.0044 & 2525.03 & 278 & 3632.25 & 24.41 & 1.0242 & 3745.27 \\
\hline 193 & 2525.09 & 1.868 & 1.0046 & 2538.51 & 279 & & & & 3760.39 \\
\hline 194 & 2538.11 & 1.949 & 1.0047 & 2552 & 280 & 3658.31 & 25.48 & 1.0249 & 3775.54 \\
\hline 195 & 2551.13 & 2.033 & 1.0048 & 2565.5 & 281 & 3671.34 & 26.028 & 1.0252 & 3790.71 \\
\hline 196 & 2564.15 & 2.119 & 1.005 & 2579.01 & 282 & & & & \\
\hline 197 & 2577.17 & 2.208 & 1.0051 & 2592.54 & 283 & 3697.4 & 27.147 & 1.0259 & 3821.13 \\
\hline 198 & 2590.2 & 2.3 & 1.0052 & 2606.08 & 284 & 3710.43 & 27.719 & 263 & 3836.39 \\
\hline 199 & 2603.22 & 2.394 & 1.0054 & 2619.63 & 285 & 3723.46 & 28.299 & 1.0266 & 3851.67 \\
\hline 200 & 2616.24 & 2.492 & 1.0055 & 2633.2 & 286 & 3736.49 & 28.8 & 1.027 & 3866.97 \\
\hline 201 & 2629.26 & 2.593 & 1.0057 & 2646.77 & 287 & 3749.53 & 29.4 & 1.0273 & 3882.3 \\
\hline 202 & 2642.28 & 2.696 & 1.0058 & 2660.36 & 288 & 3762.56 & 30.089 & 1.0277 & 3897.66 \\
\hline 203 & 2655.3 & 2.803 & 1.006 & 2673.97 & 289 & 3775.59 & 30.703 & 1.028 & 3913.05 \\
\hline 204 & 2668.32 & 2.913 & 1.0061 & 268 & 290 & 62 & & & 3928.46 \\
\hline 205 & 2681.35 & 3.027 & 1.0063 & 2701.22 & 291 & 3801.65 & & 1.0288 & 3943.9 \\
\hline 206 & 2694.37 & 3.143 & 1.0064 & 2714 & 292 & 3814.68 & 32. & 1.0291 & 3959.37 \\
\hline 207 & 2707.39 & 3.263 & 1.0066 & 2728.53 & 293 & 27.72 & 33.244 & 295 & 3974.87 \\
\hline 208 & 2720.41 & 3.387 & 1.0068 & 2742.2 & 294 & 3840.75 & 33.9 & 1.0299 & 3990.39 \\
\hline 209 & 2733.43 & 3.51 & 1.0069 & 275 & 295 & .78 & 34. & 302 & 4005.94 \\
\hline 210 & 2746.46 & 3.645 & 1.0071 & 2769. & 296 & 3866.81 & & 1.0306 & 4021.52 \\
\hline 211 & 2759.48 & 3.779 & 1.0073 & 2783 & 297 & 3879 & 35. & 1.03 & 4037.13 \\
\hline 212 & 2772.5 & 3.917 & 1.0074 & 2797.05 & 298 & 3892.88 & 36.616 & 1.0314 & 4052.77 \\
\hline 213 & 2785.52 & 4.058 & 1.0076 & 2810.8 & 299 & 3905.91 & 37.3 & 1.0318 & 4068.43 \\
\hline 214 & 2798.55 & 4.204 & 1.0078 & 2824.56 & 300 & 3918.94 & 38.028 & 1.0321 & 4084.13 \\
\hline 215 & 2811.57 & 4.353 & 1.008 & 2838 & 301 & 3931.98 & 38.7 & 1.0325 & 4099.85 \\
\hline 216 & 2824.59 & 4.50 & 1.0081 & 2852. & 302 & 3945.01 & 39.4 & 1.0329 & 4115.6 \\
\hline 217 & 2837.61 & 4.664 & 1.0083 & 2865.95 & 303 & 3958.04 & 40.214 & 1.0333 & 4131.38 \\
\hline 218 & 2850.64 & 4.825 & 1.0085 & 2879.78 & 304 & 3971.08 & 40.961 & 1.0337 & 4147.18 \\
\hline 219 & 2863.66 & 4.991 & 1.0087 & 2893.62 & 305 & 3984.11 & 41.717 & 1.0341 & 4163.02 \\
\hline 220 & 2876.68 & 5.16 & 1.0089 & 2907.48 & 306 & 3997.14 & & & 4178.89 \\
\hline 221 & 2889.71 & 5.334 & 1.0091 & 2921.36 & $30^{\circ}$ & 4010.18 & 43.258 & 1.0349 & 4194.78 \\
\hline 222 & 2902.73 & 5.513 & 1.0093 & 2935.25 & 308 & 4023.21 & 44.043 & 1.0353 & 4210.71 \\
\hline 223 & 2915.76 & 5.695 & 1.0095 & 2949.16 & 309 & 4036.24 & 44.836 & 1.0357 & 4226.66 \\
\hline 224 & 2928.78 & 5.883 & 1.0097 & 2963.09 & 310 & 4049.28 & 45.64 & 1.0361 & 4242.65 \\
\hline 225 & 2941.8 & 6.074 & 1.0099 & 2977.04 & 311 & 4062.31 & 46.453 & 1.0365 & 4258.66 \\
\hline 226 & 2954.83 & 6.271 & 1.0101 & 2991 & 312 & 4075.34 & 47.276 & 1.0369 & 4274.71 \\
\hline 227 & 2967.85 & 6.472 & 1.0103 & 3004.98 & 313 & 4088.38 & 48.108 & 1.0373 & 4290.78 \\
\hline 228 & 2980.88 & 6.677 & 1.0105 & 3018.98 & 314 & 4101.41 & 48.95 & 1.0377 & 4306.89 \\
\hline 229 & 2993.9 & 6.888 & 1.0107 & 3033 & 315 & 4114.45 & 49.802 & 1.0381 & 4323.02 \\
\hline 230 & 3006.93 & 7.103 & 1.0109 & 3047.03 & 316 & 4127.48 & 50.664 & 1.0385 & 4339.19 \\
\hline 231 & 3019.95 & 7.323 & 1.0112 & 3061.08 & 317 & 4140.52 & 51.535 & 1.039 & 4355.38 \\
\hline 232 & 3032.98 & 7.549 & 1.0114 & 3075.16 & 318 & 4153.55 & 52.417 & 1.0394 & 4371.61 \\
\hline 233 & 3046 & 7.779 & 1.0116 & 3089.25 & 319 & 4166.59 & 53.308 & 1.0398 & 4387.86 \\
\hline 234 & 3059.03 & 8.014 & 1.0118 & 3103.35 & 320 & 4179.62 & 54.209 & 1.0402 & 4404.15 \\
\hline 235 & 3072.05 & 8.255 & 1.0121 & 3117.48 & 321 & 4192.66 & 55.121 & 1.0407 & 4420.47 \\
\hline
\end{tabular}


Table A.II. Partition function for ${ }^{81} \mathrm{BrO}$

\begin{tabular}{|c|c|c|c|c|c|c|c|c|c|}
\hline$T(K)$ & $Z_{\mathrm{Rot}}^{3 / 2}(T)$ & $Z_{\mathrm{Rot}}^{1 / 2}(T)$ & $\mathrm{Z}_{\mathrm{Vib}}(T)$ & $Z_{\mathrm{Tot}}(T)$ & $T(K)$ & $Z_{\mathrm{Rot}}^{3 / 2}(T)$ & $Z_{\mathrm{Rot}}^{1 / 2}(T)$ & $\mathrm{Z}_{\mathrm{Vib}}(T)$ & $Z_{\mathrm{Tot}}(T)$ \\
\hline 150 & 1973.4 & 0.18 & 1.001 & 1975.5 & 236 & 3097.82 & 8.53 & 1.0123 & 3144.56 \\
\hline 151 & 1986.47 & 0.2 & 1.001 & 1988.69 & 237 & 3110.9 & 8.79 & & \\
\hline 152 & 1999.54 & 0.21 & 1.0011 & 2001.88 & 238 & 3123.98 & 9.04 & 1.0128 & 3173.04 \\
\hline 153 & 2012.61 & 0.23 & 1.0011 & 2015.08 & 239 & 3137.06 & 9.31 & & 3187.3 \\
\hline 154 & 2025.68 & 0.24 & 1.0012 & 2028.28 & 240 & 3150.14 & 9.58 & & 3201.59 \\
\hline 155 & 2038.75 & 0.26 & 1.0012 & 2041.48 & 241 & 3163.22 & 9.85 & 1.0135 & 3215.89 \\
\hline 156 & 2051.82 & 0.27 & 1.0013 & 2054.7 & 242 & 3176.3 & 10.13 & 1.0137 & 3230.22 \\
\hline 157 & 2064.89 & 0.29 & 1.0013 & 2067.92 & 243 & 189.38 & 10.42 & & .56 \\
\hline 158 & 2077.96 & 0.31 & 1.0014 & 2081.14 & 244 & 3202.46 & 10.71 & 1.0142 & 258.93 \\
\hline 159 & 2091.03 & 0.33 & 1.0014 & 2094.37 & 245 & 54 & 11 & 1.0145 & .32 \\
\hline 160 & 2104.1 & 0.35 & 1.0015 & 2107.61 & 246 & 3228 & & 48 & 3287.72 \\
\hline 161 & 2117.17 & 0.37 & 1.0016 & 2120.85 & 247 & 3241 & 11.6 & 1.015 & 3302.15 \\
\hline 162 & 2130.25 & 0.4 & 1.0016 & 2134.1 & 248 & 325 & 11. & & 3316.6 \\
\hline 163 & 2143.32 & 0.42 & 1.0017 & 2147.36 & 249 & 3267 & 12.25 & & 3331.07 \\
\hline 164 & 2156.39 & 0.45 & 1.0018 & 2160.62 & 250 & 3280.95 & 12. & 1.01 & 3345.57 \\
\hline 165 & 2169.46 & 0.47 & 1.0018 & 2173.89 & 251 & 3294. & 12.91 & 61 & 360.08 \\
\hline 166 & 2182.53 & 0.5 & 1.0019 & 2187.17 & 252 & 3307 & 13.25 & 1.0163 & 3374.62 \\
\hline 167 & 2195.6 & 0.53 & 1.002 & 2200.45 & 253 & 3320 & 13. & 1.0166 & 3389.18 \\
\hline 168 & 2208.67 & 0.56 & 1.002 & 2213.74 & 254 & 3333.27 & 13.95 & $1.01 \mathrm{C}$ & 3403.76 \\
\hline 169 & 2221.74 & 0.59 & 1.0021 & 2227.04 & 255 & 3346 & 14.3 & 1.0172 & 3418.36 \\
\hline 170 & 2234.82 & 0.62 & 1.0022 & 2240.35 & 256 & 3359.44 & 14.68 & 1.0174 & 432.99 \\
\hline 171 & 2247.89 & 0.66 & 1.0023 & 2253.67 & 257 & 3372 & & 77 & 3447.64 \\
\hline 172 & 2260.96 & 0.69 & 1.0024 & 2266.99 & 258 & 3385 & 15. & 1.0 & 3462.31 \\
\hline 173 & 2274.03 & 0.73 & 1.0024 & 2280.32 & 259 & 3398.68 & 15.81 & 1.0183 & 3477 \\
\hline 174 & 2287.1 & 0.77 & 1.0025 & 2293.66 & 260 & 3411 & 16.21 & 1.0186 & 3491.72 \\
\hline 175 & 2300.18 & 0.81 & 1.0026 & 2307.01 & 261 & 3424. & 16.61 & 1.0189 & 3506.46 \\
\hline 176 & 2313.25 & 0.85 & 1.0027 & 2320.37 & 262 & 3437.93 & 17.01 & 1.0192 & 3521.23 \\
\hline 177 & 2326.32 & 0.9 & 1.0028 & 2333.74 & 263 & 3451.02 & 17.43 & 1.0195 & 3536.01 \\
\hline 178 & 2339.39 & 0.94 & 1.0029 & 2347.11 & 264 & 3464.1 & 17.85 & 1.0198 & 3550.83 \\
\hline 179 & 2352.47 & 0.99 & 1.003 & 2360.5 & 265 & 3477.18 & 18. & 1.02 & 3565.66 \\
\hline 180 & 2365.54 & 1.04 & 1.0031 & 2373.89 & 266 & 3490.27 & 18.7 & 1.02 & 3580.52 \\
\hline 181 & 2378.61 & 1.09 & 1.0032 & 2387.3 & 267 & 3503.35 & 19.15 & 1.0207 & 3595.4 \\
\hline 182 & 2391.69 & 1.14 & 1.0033 & 2400.71 & 268 & 3516.43 & 19.6 & 1.021 & 3610.31 \\
\hline 183 & 2404.76 & 1.2 & 1.0034 & 2414.14 & 269 & 3529.52 & 20.06 & 1.0213 & 3625.24 \\
\hline 184 & 2417.83 & 1.26 & 1.0035 & 2427.57 & 270 & 3542.6 & 20.52 & 1.0216 & 3640.2 \\
\hline 185 & 2430.91 & 1.32 & 1.0036 & 2441.02 & 271 & 3555.68 & 20.99 & 1.0219 & 3655.18 \\
\hline 186 & 2443.98 & 1.38 & 1.0037 & 2454.47 & 272 & 3568.77 & 21.47 & 1.0223 & 3670.19 \\
\hline 187 & 2457.05 & 1.44 & 1.0038 & 2467.94 & 273 & 3581.85 & 21.96 & 1.0226 & 3685.22 \\
\hline 188 & 2470.13 & 1.51 & 1.004 & 2481.42 & 274 & 3594.94 & 22.45 & 1.0229 & 3700.28 \\
\hline 189 & 2483.2 & 1.58 & 1.0041 & 2494.9 & 275 & 3608.02 & 22.96 & 1.0232 & 3715.36 \\
\hline 190 & 2496.28 & 1.65 & 1.0042 & 2508.4 & 276 & 3621.1 & 23.47 & 1.0236 & 3730.47 \\
\hline 191 & 2509.35 & 1.72 & 1.0043 & 2521.91 & 277 & 3634.19 & 23.98 & 1.0239 & 3745.6 \\
\hline 192 & 2522.43 & 1.8 & 1.0044 & 2535.44 & 278 & 3647.27 & 24.51 & 1.0242 & 3760.76 \\
\hline
\end{tabular}


Table A.II. (Continued)

\begin{tabular}{|c|c|c|c|c|c|c|c|c|c|}
\hline$T(K)$ & $Z_{\mathrm{Rot}}^{3 / 2}(T)$ & $Z_{\mathrm{Rot}}^{1 / 2}(T)$ & $\mathrm{Z}_{\mathrm{Vib}}(T)$ & $Z_{\text {Tot }}(T)$ & $T(K)$ & $Z_{\mathrm{Rot}}^{3 / 2}(T)$ & $Z_{\mathrm{Rot}}^{1 / 2}(T)$ & $\mathrm{Z}_{\mathrm{Vib}}(T)$ & $Z_{\text {Tot }}(T)$ \\
\hline 193 & 2535.5 & 1.88 & 1.0046 & 2548.97 & 279 & 3660.36 & 25.04 & 1.0246 & 3775.94 \\
\hline 194 & 2548.57 & 1.96 & 1.0047 & 2562.52 & 280 & 3673.44 & 25.58 & 1.0249 & 3791.15 \\
\hline 195 & 2561.65 & 2.04 & 1.0048 & 2576.07 & 281 & 3686.53 & 26.13 & 1.0252 & 3806.39 \\
\hline 196 & 2574.72 & 2.13 & 1.005 & 2589.64 & 282 & 3699.61 & 26.69 & 1.0256 & 3821.65 \\
\hline 197 & 2587.8 & 2.22 & 1.0051 & 2603.23 & 283 & 3712.7 & 27.26 & 1.0259 & 3836.94 \\
\hline 198 & 2600.87 & 2.31 & 1.0052 & 2616.82 & 284 & 3725.78 & 27.83 & 1.0263 & 3852.26 \\
\hline 199 & 2613.95 & 2.4 & 1.0054 & 2630.43 & 285 & 3738.87 & 28.41 & 1.0266 & 3867.6 \\
\hline 200 & 2627.03 & 2.5 & 1.0055 & 2644.05 & 286 & 3751.96 & 29 & 1.027 & 3882.97 \\
\hline 201 & 2640.1 & 2.6 & 1.0057 & 2657.69 & 287 & 3765.04 & 29.6 & 1.0273 & 3898.37 \\
\hline 202 & 2653.18 & 2.71 & 1.0058 & 2671.33 & 288 & 3778.13 & 30.21 & 1.0277 & 3913.79 \\
\hline 203 & 2666.25 & 2.81 & 1.006 & 2685 & 289 & 3791.21 & 30.83 & 1.02 & 392 \\
\hline 204 & 2679.33 & 2.93 & 1.0061 & 2698.67 & 290 & 3804.3 & 31.45 & 1.0284 & 3944 \\
\hline 205 & 2692.4 & 3.04 & 1.0063 & 2712.36 & 291 & 17.39 & 32.09 & 1.0288 & 3960.22 \\
\hline 206 & 2705.48 & 3.16 & 1.0064 & 2726.06 & 292 & 3830.47 & 32.73 & 1.0291 & 3975.76 \\
\hline 207 & 2718.56 & 3.28 & 1.0066 & 2739.78 & 293 & 843.56 & 33.38 & 1.0295 & 3991.32 \\
\hline 208 & 2731.63 & 3.4 & 1.0068 & 2753.51 & 294 & 56.64 & 34.04 & & 4006.91 \\
\hline 209 & 2744.71 & 3.53 & 1.0069 & 2767.26 & 295 & 3869.73 & 34.71 & 1.0302 & 4022.52 \\
\hline 210 & 2757.79 & 3.66 & 1.0071 & 2781.02 & 296 & 3882.82 & 35.38 & 1.0306 & 4038.17 \\
\hline 211 & 2770.86 & 3.79 & 1.0073 & 2794.79 & 297 & 3895.91 & 36.07 & 1.031 & 4053.84 \\
\hline 212 & 2783.94 & 3.93 & 1.0074 & 2808.59 & 298 & 08.99 & 36.77 & 0314 & 4069.54 \\
\hline 213 & 2797.02 & 4.07 & 1.0076 & 2822.39 & 299 & 3922.08 & 37.47 & 1.0318 & 4085.27 \\
\hline 214 & 2810.09 & 4.22 & 1.0078 & 2836.21 & 300 & 3935 & 38. & 1.0321 & 4101.03 \\
\hline 215 & 2823.17 & 4.37 & 1.008 & 2850.05 & 301 & 3948.25 & 38.91 & 1.0325 & 4116.82 \\
\hline 216 & 2836.25 & 4.52 & 1.0081 & 2863.91 & 302 & 3961.34 & 39.64 & 1.0329 & 4132.63 \\
\hline 217 & 2849.33 & 4.68 & 1.0083 & 2877.77 & 303 & 3974.43 & 40.38 & 1.0333 & 4148.48 \\
\hline 218 & 2862.4 & 4.84 & 1.0085 & 2891.66 & 304 & 3987.52 & 41.13 & 1.0337 & 4164.35 \\
\hline 219 & 2875.48 & 5.01 & 1.0087 & 2905.56 & 305 & 4000.61 & 41.8 & 1.03 & 4180.26 \\
\hline 220 & 2888.56 & 5.18 & 1.0089 & 2919.48 & 306 & 4013.69 & 42.66 & 1.0345 & 4196.19 \\
\hline 221 & 2901.64 & 5.36 & 1.0091 & 2933.42 & 307 & 4026.78 & 43.43 & 1.0349 & 4212.15 \\
\hline 222 & 2914.71 & 5.53 & 1.0093 & 2947.37 & 308 & 4039.87 & 44.22 & 1.0353 & 4228.14 \\
\hline 223 & 2927.79 & 5.72 & 1.0095 & 2961.34 & 309 & 4052.96 & 45.02 & 1.0357 & 4244.16 \\
\hline 224 & 2940.87 & 5.91 & 1.0097 & 2975.32 & 310 & 4066.05 & 45.83 & 1.0361 & 4260.22 \\
\hline 225 & 2953.95 & 6.1 & 1.0099 & 2989.33 & 311 & 4079.13 & 46.64 & 1.0365 & 4276.3 \\
\hline 226 & 2967.03 & 6.3 & 1.0101 & 3003.35 & 312 & 4092.22 & 47.47 & 1.0369 & 4292.41 \\
\hline 227 & 2980.11 & 6.5 & 1.0103 & 3017.39 & 313 & 4105.31 & 48.3 & 1.0373 & 4308.55 \\
\hline 228 & 2993.18 & 6.7 & 1.0105 & 3031.44 & 314 & 4118.4 & 49.15 & 1.0377 & 4324.72 \\
\hline 229 & 3006.26 & 6.92 & 1.0107 & 3045.52 & 315 & 4131.49 & 50 & 1.0381 & 4340.92 \\
\hline 230 & 3019.34 & 7.13 & 1.0109 & 3059.61 & 316 & 4144.58 & 50.87 & 1.0385 & 4357.16 \\
\hline 231 & 3032.42 & 7.35 & 1.0112 & 3073.72 & 317 & 4157.67 & 51.75 & 1.039 & 4373.42 \\
\hline 232 & 3045.5 & 7.58 & 1.0114 & 3087.85 & 318 & 4170.76 & 52.63 & 1.0394 & 4389.71 \\
\hline 233 & 3058.58 & 7.81 & 1.0116 & 3102 & 319 & 4183.85 & 53.53 & 1.0398 & 4406.04 \\
\hline 234 & 3071.66 & 8.05 & 1.0118 & 3116.17 & 320 & 4196.94 & 54.43 & 1.0402 & 4422.39 \\
\hline 235 & 3084.74 & 8.29 & 1.0121 & 3130.36 & & & & & \\
\hline
\end{tabular}


species respectively. In these Tables are detailed the rotational contribution due to the $X_{1}^{2} \Pi_{3 / 2}$ and $X_{1}^{2} \Pi_{1 / 2}$ spin components $\left(Z_{\text {Rot }}^{3 / 2}(T)\right.$ and $Z_{\text {Rot }}^{1 / 2}(T)$, respectively) the vibrational contribution $Z_{\mathrm{Vib}}(T)$ together with the final result $Z_{\mathrm{Tot}}(T)$.

\footnotetext{
Notes

${ }^{1}$ In the following, each molecule is identified by a number which is actually the molecule code number used in HITRAN. The exception is $\mathrm{BrO}$ which is absent in HITRAN and for which the number 40 was associated.

${ }^{2}$ It is worth stressing that for oxygen the broadening coefficients given in the MASTER database are the $\mathrm{N}_{2}$ - and $\mathrm{O}_{2}$-broadening coefficients and not the air and self broadening coefficients which are given for all other molecular species.

${ }^{3}$ In Equation (8) the decimals, which have no real physical meaning are given in order to reproduce the list of line broadening coefficients quoted in MASTER.

${ }^{4}$ The ${ }^{79} \mathrm{BrO}$ and ${ }^{81} \mathrm{BrO}$ partition functions for the $150-320 \mathrm{~K}$ temperatures range have been deposited as supplementary materiel at the Journal library.
}

\section{References}

Amano, T., Yoshinaga, A., and Hirota, E., 1972: Microwave spectrum of the BrO radical equilibrium structure and dipole moment, J. Mol. Spectrosc. 44, 594-598.

Amano, T. and Hirota, E., 1974: Microwave spectrum of the molecular oxygen in the excited vibrational state, J. Mol. Spectrosc. 53, 346-363.

De Backer-Barilly, M. R. and Barbe, A., 2001: Absolute intensities of the $10 \mu \mathrm{m}$ bands of ${ }^{16} \mathrm{O}_{3}, J$. Mol. Spectrosc. 205, 43-53.

Bakri, B., Colmont, J.-M., Rohart, F., and Wlodarczak, G., 2002: $K$-dependence of pressure broadening coefficients in symmetric top molecules: Cases of ${ }^{12} \mathrm{CH}_{3}{ }^{35} \mathrm{Cl}$ and ${ }^{12} \mathrm{CH}_{3} \mathrm{C}^{14} \mathrm{~N}$, Poster J32, "The 17th International Conference on High Resolution Molecular Spectroscopy", Prague, Sept 1-5 (2002).

Ballard, J., Johnston, W. B., Moffat, P. H., and Llewellyn-Jones, D. T., 1985: Experimental determination of the temperature dependence of nitrogen broadened line widths in the $1 \leftarrow 0$ band of $\mathrm{HCl}$, J. Quant. Spectrosc. Radiat. Transfer. 33, 365-371.

Baron, P., Ricaud, P., de La Noë, J., Eriksson, J. E. P., Merino, F., Ridal, M., and Murtagh, D., 2002: Studies for the Odin Sub-Millimeter Radiometer: II. Retrieval methodology, Can. J. Phys., 80, 341-356.

Bauer, A., Godon, M., and Duterage, B., 1985: Self- and air-broadened linewidths of the $183 \mathrm{GHz}$ absorption in water vapor, J. Quant. Spectrosc. Radiat. Transfer. 33, 167-175.

Bauer, A., Duterage, B., and Godon, M., 1986: Temperature dependence of water-vapor absorption in the wing of the $183 \mathrm{GHz}$ line, J. Quant. Spectrosc. Radiat. Transfer. 36, 307-318.

Bauer, A., Godon, M., Kheddar, M., Hartmann, J.-M., Bonamy, J., and Robert, D. 1987: Temperature and perturber dependences of water-vapor $380 \mathrm{GHz}$-line broadening, J. Quant. Spectrosc. Radiat. Transfer. 37, 531-539.

Bauer, A., Godon, M., Kheddar, M., and Hartmann, J.-M., 1989: Temperature and perturber dependences of water vapor line-broadening. Experiments at $183 \mathrm{GHz}$, calculations below $1000 \mathrm{GHz}$, J. Quant. Spectrosc. Radiat. Transfer. 41, 49-54.

Bauer, A. and Godon, M., 1991: Temperature dependence of water-vapor absorption in linewings at $190 \mathrm{GHz}$, J. Quant. Spectrosc. Radiat. Transfer. 46, 211-220.

Bauer, A., Godon, M., Carlier, J., Ma, Q., and Tipping, R. H., 1993: Absorption by $\mathrm{H}_{2} \mathrm{O}$ and $\mathrm{H}_{2} \mathrm{O}-\mathrm{N}_{2}$ mixtures at $153 \mathrm{GHz}$, J. Quant. Spectrosc. Radiat. Transfer. 50, 463-475.

Bauer, A., Godon, M., Carlier, J., and Ma, Q., 1995: Water vapor absorption in the atmospheric window at $239 \mathrm{GHz}$, J. Quant. Spectrosc. Radiat. Transfer. 53, 411-423. 
Bauer, A., Birk, M., Wagner, W., Colmont, J.-M., Priem, D., Wlodarczak, G., Buehler, S., Von Engeln, A., Künzi, K., and Perrin, A., 1998a: Study on a spectroscopic database for millimeter and submillimeter wavelength, Final Report of ESA $N^{\circ} 11581 / 95 / N L / C N$ (1998).

Bauer, A., Godon, M., Carlier, J., and Gamache, R. R., 1998b: Continuum in the windows of the water vapor spectrum. Absorption of $\mathrm{H}_{2} \mathrm{O}-\mathrm{Ar}$ at $239 \mathrm{GHz}$ and linewidth calculations, J. Quant. Spectrosc. Radiat. Transfer. 59, 273-285.

Benner, D., Malathy, Ch., Devi, V., Blake, T. A., Brown, L. R., Toth, R. A., and Smith, M. A. H., 2004: Air broadening parameters in the $v_{3}$ band of ${ }^{14} \mathrm{~N}^{16} \mathrm{O}_{2}$ using a multispectrum fitting technique. RB06, 59th Ohio State International Symposium on Molecular Spectroscopy, Ohio (2004).

De Bievre, P., Holden, N. E., and Barnes, I. L., 1984: Isotopic abundances and atomic weights of the elements, J. Phys. Chem. Ref. Data 13, 809-891.

Birk, M., Wagner, W., Flaud, J.-M., and Hausamann, D., 1994a: Linestrengths in the $v_{3}-v_{3}$ hot band of ozone, J. Mol. Spectrosc. 163, 262-275.

Birk, M., Wagner, W., and Flaud, J.-M., 1994b: Experimental linestrengths of far-infrared pure rotational transitions of ozone, J. Mol. Spectrosc. 163, 245-261.

Birk, M., Colmont, J.-M., Priem, D., Wagner, W., and Wlodarczak, G., 1997: Fifteenth Colloquium on High Resolution Molecular Spectroscopy, Glasgow, Scotland, 7-11 September 1997, Poster F4, (1997): $\mathrm{N}_{2}, \mathrm{O}_{2}$, and Air-Broadening Coefficients of the $J=3-2$ line of $\mathrm{CO}$ and the $J=$ 342,32-341,33 line of $\mathrm{O}_{3}$, Measured with two Techniques: Tunable Microwave Source and Fourier Transform Spectroscopy (F4).

Blanquet, G., Walrand, J., and Bouanich, J.-P., 1993a: Diode laser measurements of $\mathrm{O}_{2}$-broadening in the $v_{3}$ band of $\mathrm{CH}_{3}^{35} \mathrm{Cl}, \mathrm{J}$. Mol. Spectrosc. 159, 137-143.

Blanquet, G., Walrand, J., and Bouanich, J.-P., 1993b: Diode laser measurements of $\mathrm{N}_{2}$-broadening in the $v_{3}$ band of $\mathrm{CH}_{3}^{35} \mathrm{Cl}$, J. Mol. Spectrosc. 160, 253-257.

Bocquet, R., Demaison, J., Poteau, L., Liedtke, M.. Belov, S., Yamada, K. M. T., Winnewisser, G., Gerke, C., Gripp, J., and Köhler, Th., The Ground State Rotational Spectrum of Formaldehyde, 1996: Mol. Spectrosc. 177, 154-159.

Bouanich, J.-P., Walrand, J., Alberty, S., and Blanquet, G., 1987: Laser Measurements of OxygenBroadened line widths in the $v_{1}$ Band of OCS, J. Mol. Spectrosc. 123, 37-47.

Bouanich, J.-P., Blanquet, G., and Walrand, J., 1993: Theoretical $\mathrm{O}_{2}$ - and $\mathrm{N}_{2}$-broadening coefficients for methyl chloride spectral lines, J. Mol. Spectrosc. 161, 416-426.

Bouanich, J.-P., Blanquet, G., Populaire, J. C., and Walrand, J., 2001: Broadening for methyl chloride at low temperature by diode laser spectroscopy, J. Mol. Spectrosc. 208, 72-78.

Brown, J. M., Byfleet, C. R., Howard, B. J., and Russell, D. K., 1972: The electron spectrum of the BrO radical equilibrium structure and dipole moment, Mol. Phys. 23, 457-468.

Brown, L., Farmer, C. B., Rinsland, C. P., and Toth, R. A., 1987: Molecular line parameters for the Atmospheric Molecule Trace Spectroscopy experiment, Appl. Opt. 26, 5154-5182.

Brown, L. R. and Plymate, J., 1996: $\mathrm{H}_{2}$-Broadened $\mathrm{H}_{2}{ }^{16} \mathrm{O}$ in four infrared bands between 55 and 4045 $\mathrm{cm}^{-1}$, J. Quant. Spectrosc. Radiat. Transfer 56, 263-282.

Buehler, S. A., Eriksson, P., Kuhn, T., van Engeln, A., and Verdes, C. L., 2004: ARTS, the Atmospheric Radiative Transfer Simulator, J. Quant. Spectrosc. Radiat. Transfer. 91, 65-93.

Burkholder, J. B., Hammer, P. D., Howard, C. J., Maki, A. G., Thompson, G., and Chackerian, C., 1987: Infrared measurements of the ClO radical, J. Mol. Spectrosc. 124, 139-161.

Butler, J. E., Kawaguchi, K., and Hirota, E., 1984: Infrared diode laser spectroscopy of the BrO radical, J. Mol. Spectrosc. 104, 372-379.

Carpenter, J. H., 1974: The microwave spectrum and structure of carbonyl fluoride, J. Mol. Spectrosc. 50, 182-201.

Carpenter, J. H. and Seo, P., 1985: The millimeter-wave spectrum of methyl chloride, J. Mol. Spectrosc. $113,355-361$. 
Cazzoli, G. and De Lucia, F. C., 1979: Millimeter wave spectrum of $\mathrm{HNO}_{3}$, J. Mol. Spectrosc. 76, 131-141.

Cazzoli, G., Degli Esposti, C., Favero, P. G., and Severi, G., 1981: Microwave spectra of ${ }^{16} \mathrm{O}^{17} \mathrm{O}$ and ${ }^{18} \mathrm{O}^{16} \mathrm{O}$, Nuovo Cimento-B 62B, 243-254.

Cazzoli, G., Dore, L., Puzzarini, C., and Beninati, S., 2002a: Millimeter- and submillimeter-wave spectrum of $\mathrm{C}^{17} \mathrm{O}$. Rotational hyperfine structure analyzed using the Lamb-dip technique, Phys. Chem. Chem. Phys. 4, 3575-3577.

Cazzoli, G., Dore, L., Cludi, L., Puzzarini, C., and Beninati, S., 2002b: Hyperfine structure of the $J=1 \leftarrow 0$ transition of ${ }^{13} \mathrm{CO}, J$. Mol. Spectrosc. 215, 160-162.

Cazzoli, G. and Puzzarini, C., 2004: Hyperfine structure of the $J=1 \leftarrow 0$ transition of $\mathrm{H}^{35} \mathrm{Cl}$ and $\mathrm{H}^{37} \mathrm{Cl}$, J. Mol. Spectrosc. 226, 161-168.

Cazzoli, G., Dore, L., Puzzarini, C., Bakri, B., Colmont, J.-M., Rohart, F., Wlodarczak, 2005: Experimental determination of air-broadening parameters of pure rotational transitions of $\mathrm{HNO}_{3}$ : intercomparison of measurements by using different techniques, J. Mol. Spectrosc. 229, 158-169.

Chackerian, C., Goorvitch, D., and Giver, L. R., 1985: HCl vibrational fundamental band: line intensities and temperature dependence of self-broadening coefficients, J. Mol. Spectrosc. 113, 373-387.

Chance, K., Jucks, K. W., Johnson, D. G., and Traub, W. A., 1994a: The Smithsonian Astrophysical Observatory Database SAO92, J. Quant. Spectrosc. Radiat. Transfer 52, 447-457.

Chance, K., DeNatale, P., Bellini, M., Inguscio, M., DiLonardo, G., and Fusina, L., 1994b: Pressure broadening of the $2.4978 \mathrm{THz}$ rotational lines of $\mathrm{HO}_{2}$ by $\mathrm{N}_{2}$ and $\mathrm{O}_{2}$, J.Mol. Spectrosc. 163, 67-70.

Claveau, C., Camy-Peyret, C., Valentin, A., and Flaud, J.-M., 2001: Absolute intensities of the $v_{1}$ and $\nu_{3}$ bands of ${ }^{16} \mathrm{O}_{3}$, J. Mol. Spectrosc. 206, 115-125.

Cohen, E. A., Pickett, H. M., and Geller, M., 1981: The rotational spectrum and molecular parameters of $\mathrm{BrO}$ in the ${ }^{2} \Pi_{3 / 2}$ state, J. Mol. Spectrosc. 87, 459-470.

Cohen, E. A., Pickett, H. M., and Geller, M., 1984: The submillimeter spectrum of ClO, J . Mol. Spectrosc. 106, 430-435.

Cohen, E. A. and Lewis-Bevin, W., 1991: Further measurements of the rotational spectrum of $\mathrm{COF}_{2}$ : Improved molecular constants for the ground and $v_{2}$ states, J. Mol. Spectrosc. 148, 378-384.

Colmont, J.-M. and Semmoud-Monnanteuil, N., 1987: Pressure broadening of the $\mathrm{N}_{2} \mathrm{O} J=9 \leftarrow 8$ rotational transition by $\mathrm{N}_{2} \mathrm{O}, \mathrm{N}_{2}$ and $\mathrm{O}_{2}$, J. Mol. Spectrosc. 126, 240-242.

Colmont, J.-M., Priem, D., Wlodarczak, G., and Gamache, R. R., 1999: Measurements and calculations of the halfwidth of two rotational transitions of water vapor perturbed by $\mathrm{N}_{2}, \mathrm{O}_{2}$, and air, J. Mol. Spectrosc. 193, 233-243.

Colmont, J.-M., Bakri, B., Rohart, F., and Wlodarczak, G., 2003: Experimental determination of pressure broadening parameters of millimeter wave transitions of $\mathrm{HNO}_{3}$ perturbed by $\mathrm{N}_{2}$ and $\mathrm{O}_{2}$ and their temperature dependences, J. Mol. Spectrosc. 220, 52-57.

Coudert, L. H., 1994: Analysis of the rotational energy levels of water and determination of the potential energy function for the bending $v_{2}$ mode, J. Mol. Spectrosc. 165, 406-425.

Coudert, L. H., 1999: Line frequency and line intensity analyses of water vapor, Mol. Phys. 96, 941-954.

Cox, A. P. and Riveros, J. M., 1965: Microwave spectrum and structure of nitric acid, J. Chem. Phys. 42, 3106-3112.

Crownover, R. L., Booker, R. A., De Lucia, F. C., and Helminger, P., 1988: The rotational spectrum of nitric acid: The first five vibrational states, J. Quant. Spectrosc. Radiat. Transfer 40, 39-46.

Crownover, R. L., De Lucia, F. C., and Herbst, E., 1990: The submillimeter-wave spectrum of ${ }^{16} \mathrm{O}^{18} \mathrm{O}$, Astrophys. J. Lett. 349, L29-31.

De La Noë, J., Lezeaux, O., Guillemin, G., Lauqué, R., Baron, P., and Ricaud, Ph., 1998: A groundbased microwave radiometer dedicated to stratospheric ozone monitoring, J Geophys Res. D103, 22147-22161. 
DeLeeuw, F. H. and Dymanus, A., 1973: Magnetic properties and molecular quadrupole moment of $\mathrm{HF}$ and $\mathrm{HCl}$ by molecular beam electronic resonance spectroscopy, J. Mol. Spectrosc. 48 , 427-445.

De La Noë, J., Baudry, A., Monnanteuil, N., Colmont, J.-M., and Dierich, P., 1983: Millimeter wavelength ground based observations of two minor constituents of the atmosphere, C.R.A.S., Serie A, 296, 1243-1248.

De Lucia, F. C., Cook, R. L., Helminger, P., and Gordy, W., 1971: Millimeter and submillimeter wave rotational spectrum and centrifugal distortion effects of HDO, J. Chem. Phys. 55, 5334-5339.

De Lucia, F. C., Helminger, P., Cook, R. L., and Gordy, W., 1972a: Submillimeter microwave spectrum of $\mathrm{H}_{2}{ }^{18} \mathrm{O}$, Phys. Rev. A6, 1324-1326.

De Lucia, F. C., Helminger, P., Cook, R. L., and Gordy, W., 1972b: Submillimeter microwave spectrum of $\mathrm{H}_{2}{ }^{16} \mathrm{O}$, Phys. Rev. A5, 487-490.

De Lucia, F. C., Helminger, P., and Kirchhoff, W. H., 1974: Microwave spectra of molecules of astrophysical interest. V. Water vapour, J. of Phys. and Chem. Ref. Data 3, 211-219.

De Lucia, F. C. and Helminger, P., 1975: Microwave spectrum and ground state energy levels of $\mathrm{H}_{2}{ }^{17} \mathrm{O}$, J. Mol. Spectrosc. 56, 138-145.

Demaison, J., Bocquet, R., Chen, W. D., Papousek, D., Boucher, D., and Bürger, H., 1994: The far-infrared spectrum of methyl chloride: Determination and order of magnitude of the sextic centrifugal distortion constants in symmetric tops, J. Mol. Spectrosc. 166, 147-157.

Demaison, J., Buehler, S., Koulev, N., Kuhn, T., Verdes, C., Cazzoli, G., Dore, L., Puzzarini, C., Flaud, J.-M., Perrin, A., Bakri, B., Colmont, J.-M., Rohart, F., and Wlodarczak, G., 2004: Characterisation of Millimeter wave spectroscopic signatures, ESTEC contract $n^{\circ} 16377 / 02 / N L / F F$, (2004).

Depannemaecker, J. C. and Bellet, J., 1977: Rotational spectra of the ${ }^{16} \mathrm{O}_{3}$ and of the five ${ }^{18} \mathrm{O}$ isotopic species, J. Mol. Spectrosc. 66, 106-120.

Depannemaecker, J. C. and Lemaire, J., 1988: Measurement with a double-beam spectrometer of strengths and half-widths of $2 v_{2}$ and $3 v_{2}-v_{2}$ OCS Lines, J. Mol. Spectrosc. 128, 350-359.

De Valk, P., Chipperfield, M., Crewell, S., Franke, B., Goede, A., de Jonge, A., Küllmann, H., Lee, A., Mees, J., Urban, J., and Wohlgemuth, J., 1997: Airborne heterodyne measurements of stratospheric $\mathrm{ClO}, \mathrm{Hcl} ; \mathrm{O}_{3}$ and $\mathrm{N}_{2} \mathrm{O}$ during SESAME-I over Northern Europe, J Geophys. Res. D102, 1391-1398.

Dicke, R. H., 1953: The effect of collisions upon the doppler width of spectral lines, Phys. Rev. 89, 472-473.

Drouin, B. J., Miller, C. E., Müller, H. S. P., and Cohen, E. A., 2001a: The rotational spectra, isotopically independent parameters, and interatomic potentials for the $X_{1}^{2} \Pi_{3 / 2}$ and $X_{2}^{2} \Pi_{3 / 2}$ states of BrO, J. Mol. Spectrosc. 205, 128-138.

Drouin, B. J., Miller, C. E., Cohen, E. A., Wagner, W., and Birk, M., 2001b: Further investigations of the ClO rotational, J. Mol. Spectrosc. 207, 4-9.

Drouin, B. J., 2004a: Temperature dependent pressure-induced lineshape of the HCl $J=1 \leftarrow 0$ rotational transition in nitrogen and oxygen, J. Quant. Spectrosc. Radiat. Transfer. 83, 321-331.

Drouin, B. J., Gamache, R. R., and Fischer, J., 2004b: Temperature dependent pressure induced lineshape of $\mathrm{O}_{3}$ rotational transitions in air, J. Quant. Spectrosc. Radiat. Transfer 83, 6381.

Eluszkiekicz, E., Crisp, D., Zurek, R., Elson, L., Fishbein, E., Froidevaux, L., Waters, J., Grainger, R. G., Lambert, A., Harwood, R., and Peckham G., 1996: Residual circulation in the stratosphere and lower mesosphere as diagnosed from Microwave Limb Sounder data, J. of the Atmosph. Sciences 53, 217-240.

Eriksson, P., Merino, F., Murtagh, D., Baron, P., Ricaud, P., and de La Noë, J., 2002: Studies for the Odin Sub-Millimeter Radiometer: I. Radiative transfer and instrument simulation, Can. J. Phys., 80, 321-340. 
Fabricant, B., Krieger, D., and Muenter, J. S., 1977: Molecular beam electric resonance study of formaldehyde, thioformaldehyde and ketene, J. Chem. Phys. 67, 1576-1586.

Fischer, J., Gamache, R. R., Goldman, A., Rothman, L. S., and Perrin, A., 2003: Total internal partition sums for molecular species in the 2000 edition of the HITRAN database, J. Quant. Spectrosc. Radiat. Transfer 82, 401-412.

Flaud, J.-M., Camy-Peyret, C., and Toth, R. A., 1981: Water vapour line parameters from microwave to medium infrared, an atlas of $\mathrm{H}_{2}{ }^{16} \mathrm{O}, \mathrm{H}_{2}{ }^{17} \mathrm{O}$ and $\mathrm{H}_{2}{ }^{18} \mathrm{O}$ line positions and intensities between $\mathrm{O}$ and $4350 \mathrm{~cm}^{-1}$, Pergamon Press, Oxford (UK).

Flaud, J.-M., Camy-Peyret, C., Rinsland, C. P., Smith, M. A. H., and Malathy Devi, V., 1990a: Atlas of ozone spectral parameters from microwave to medium infrared, Academic Press Inc., Cambridge, Massachusetts.

Flaud, J.-M., Camy-Peyret, C., Rinsland, C. P., Malathy Devi, V., Smith, M. A. H., and Goldman, A., 1990b: Improved line parameters for ozone bands in the $10 \mu \mathrm{m}$ spectral region, Appl. Opt. 29, $3667-3671$.

Flaud, J.-M., and Bacis, R., 1998a: The ozone molecule: Infrared and microwave spectroscopy, Spectrochimica Acta 54A, 3-16.

Flaud, J.-M., Birk, M., Wagner, W., Orphal, J., Klee, S., Lafferty, W. J., 1998b: The far infrared spectrum of $\mathrm{HOCl}$ : line positions and intensities, J. Mol. Spectrosc. 191, 362367.

Flaud, J.-M., Wagner, W., Birk, M., Camy-Peyret, C., Claveau, C., De Backer-Barilly, M. R., Barbe, A., and Piccolo, C., 2003a: Ozone absorption around $10 \mu \mathrm{m}$, J. Geophys. Res. D108, doi:10.1029/2002JD002755.

Flaud, J.-M., Piccolo, C., Carli, B., Perrin, A., Coudert, L. H., Teffo, J.-L., and Brown, L., 2003b: Molecular line parameters for the MIPAS (Michelson Interferometer for Passive Atmospheric Sounding) experiment, J. of Atmos. Ocean and Optics 16, 172-182.

Galatry, R., 1961: Simultaneous effect of Doppler and foreign gas broadening on spectral lines, Phys. Rev. 122, 1218-223.

Gamache, R. R. and Davies, R. W., 1983: Theoretical calculation of molecular nitrogen broadened halfwidths of water using quantum Fourier theory, Appl. Opt. 22, 4013-4019.

Gamache, R. R., Hartmann, J.-M., and Rosenmann, L., 1994: Collisional broadening of water vapor lines-I. A survey of experimental results, J. Quant. Spectrosc. Radiat. Transfer 52, 481-499.

Gamache, R. R., Lynch, R., and Neshyba, S. P., 1998: New Developments in the Theory of PressureBroadening and Pressure-Shifting of Spectral Lines of $\mathrm{H}_{2} \mathrm{O}$ : The Complex Robert-Bonamy Formalism, J. Quant. Spectrosc. Radiat. Transfer 59, 319-335.

Gamache, R. R. and Fischer, J., 2003a: Half-widths of $\mathrm{H}_{2}{ }^{16} \mathrm{O}, \mathrm{H}_{2}{ }^{18} \mathrm{O}, \mathrm{H}_{2}{ }^{17} \mathrm{O} \mathrm{HD}{ }^{16} \mathrm{O}$ and $\mathrm{D}_{2}^{16} \mathrm{O}$ : I. Comparaison between isotopomers, J. Quant. Spectrosc. Radiat. Transfer 78, $289-304$.

Gamache, R. R. and Fischer, J., 2003b: Half-widths of $\mathrm{H}_{2}{ }^{16} \mathrm{O}, \mathrm{H}_{2}{ }^{18} \mathrm{O}, \mathrm{H}_{2}{ }^{17} \mathrm{O}, \mathrm{HD}^{16} \mathrm{O}$ and $\mathrm{D}_{2}^{16} \mathrm{O}$ : II Comparison with measurements, J. Quant. Spectrosc. Radiat. Transfer 78, 305-318.

Gamache, R. R. and Hartmann, J.-M., 2004: Collisional parameters of $\mathrm{H}_{2} \mathrm{O}$ lines: effects of vibration, J. Quant. Spectrosc. Radiat. Transfer 83, 119-147.

Gillis, H. E., Singbeil, D., Anderson, W. D., Wellington Davis, R., Gerry, M. C. L., Cohen, E. A., Pickett, H. M., Lovas, F. J., and Suenram, R. D., 1984: The microwave and millimeter-wave spectra of hypochlorous acid, J. Mol. Spectrosc 103, 466-485.

Godon, M., Carlier, J., and Bauer, A., 1992: Laboratory studies of water vapor absorption in the atmosphere window at $213 \mathrm{GHz}$, J. Quant. Spectrosc. Rad. Transfer 47, 275-285.

Golubiatnikov, G., and Krupnov, A. F., 2003: Microwave study of the rotational spectrum of oxygen molecule in the range up to $1.12 \mathrm{THz}$, J. Mol. Spectrosc. 217, 282-287.

Goyette, T. M., Ebenstein, W. L., De Lucia, F. C., and Helminger, P., 1988a: Pressure broadening of the millimeter and submillimeter wave spectra of nitric acid by oxygen and nitrogen, J. Mol. Spectrosc. 128, 108-116. 
Goyette, T. M., Ebenstein, W. L., Shostak, S. L., De Lucia, F. C., and Helminger, P., 1988b: Pressure broadening of $\mathrm{NO}_{2}, \mathrm{CF}_{2} \mathrm{Cl}_{2}$, $\mathrm{HDO}$ and $\mathrm{HOOH}$ by $\mathrm{O}_{2}$ and $\mathrm{N}_{2}$ in the millimeter wave region, $J$. Quant. Spectrosc. Radiat. Transfer 40, 129-134.

Goyette, T. M., and De Lucia, F. C., 1990: The temperature broadening of the $3_{1,3}-2_{2,0}$ transition of water $(183 \mathrm{GHz})$ between 80 and $600 \mathrm{~K}$, J. Mol. Spectrosc. 183, 346-358.

Goyette, T. M., Guo, W., De Lucia, F. C., and Helminger, P., 1991: Variable temperature pressure broadening of $\mathrm{HNO}_{3}$ in the millimeter wave spectral region, J. Quant. Spectrosc. Radiat. Transfer 46, 293-297.

Goyette, T. M., De Lucia, F. C., Dutta, J. M., and Jones, C. R., 1993a: Variable temperature pressure broadening of the $4_{1,4}-3_{2,1}$ transition of water $(380 \mathrm{GHz})$ by $\mathrm{O}_{2}$ and $\mathrm{N}_{2}$, J. Quant. Spectrosc. Radiat. Transfer 49, 485-489.

Goyette, T. M., Fergusson, D. W., De Lucia, F. C., Dutta, J. M., and Jones, C. R., 1993b: The pressure broadening of $\mathrm{HDO}$ by $\mathrm{O}_{2}, \mathrm{~N}_{2}$ and $\mathrm{H}_{2}$ between 100 and $600 \mathrm{~K}$, J. Mol. Spectrosc. 162, 366-374.

Goyette, T. M., Oesterling, L. C., Petkie, D. T., Booker, R. A., Helminger, P., and De Lucia, F. C., 1996: Rotational spectrum of $\mathrm{HNO}_{3}$ in the $v_{5}$ and $2 v_{9}$ vibrational states, J. Mol. Spectrosc. 175, 395-410.

Goyette, T. M., Cohen, E. A., and De Lucia, F. C., 1998: Pressure broadening of $\mathrm{HNO}_{3}$ by $\mathrm{N}_{2}$ and $\mathrm{O}_{2}$ : an intercomparison in the millimeter wave spectral range, J. Quant. Spectrosc. Radiat. Transfer 60, 377-384.

Harde, H., Katzenellenbogen, N., and Grischkowsky, D., 1994: Terahertz coherent transients from methyl chloride vapor, J. of Opt. Soc. of Am. B11, 1018-1030.

Harde, H., Cheville, R. A., and Grischkowsky, D., 1997a: Terahertz coherent transients from methyl chloride vapor, J. of Opt. Soc. of Am. B14, 3282-3293.

Harde, H., Cheville, R. A., and Grischkowsky, D., 1997b: Terahertz studies of collision broadened rotational lines, J. Phys. Chem. A101, 3646-3660.

Houdeau, J. P., Larvor, M., and Haeusler, C., 1980: Etude à basse température des largeurs et des déplacements des raies rovibrationnelles de la bande de $\mathrm{H}^{35} \mathrm{Cl}$ comprimé par $\mathrm{N}_{2}, \mathrm{O}_{2}, \mathrm{D}_{2}$ and $\mathrm{H}_{2}$, Can. J. Phys. 58, 318-324 (1980).

Kaiser, E. W., 1970: Dipole moment and hyperfine parameters of $\mathrm{H}^{35} \mathrm{Cl}$ and $\mathrm{D}^{35} \mathrm{Cl}$, J. Chem. Phys. 53, 1686-1703.

Klapper, G., Lewen, F., Gendriesch, R., Belov, S. P., and Winnewisser, G., 2000a: Sub-Doppler measurements of the rotational spectrum of ${ }^{13} \mathrm{C}^{16} \mathrm{O}$, J. Mol. Spectrosc. 201, 124-127.

Klapper, G., Lewen, F., Belov, S. P., and Winnewisser, G., 2000b: Sub-Doppler measurements and rotational spectrum of ${ }^{13} \mathrm{C}^{18} \mathrm{O}$, Z. Naturforsch. 55A, 441-443.

Klapper, G., Lewen, F., Gendriesch, R., Belov, S. P., and Winnewisser, G., 2001: Sub-Doppler measurements and terahertz rotational spectrum of ${ }^{12} \mathrm{C}^{18} \mathrm{O}$, Z. Naturforsch. 56A, 329-332.

Klaus, Th., Belov, S. P., and Winnewisser, G., 1998: Precise measurement of the pure rotational submillimeter-wave spectrum of $\mathrm{HCl}$ and $\mathrm{DCl}$ in their $v=0,1$ states, J. Mol. Spectrosc. 187, 109-117.

Kleiner, I., Godefroid, M., Herman M., and Mc Kellar, A. R. W., 1987: Infrared laser Stark spectrum of $\mathrm{HNO}_{3}$ at $6 \mu \mathrm{m}$, J. of the Opt. Soc. of Am. B4, 1159-1164.

Koga, Y., Takeo, H., Kondo, S., Sugie, M., Matsumura, C., McRae, G. A., Cohen, E. A., 1989: The rotational spectra, molecular structure, dipole moment, and hyperfine constants of $\mathrm{HOBr}$ and DOBr, J. Mol. Spectrosc. 138, 467-481.

Krupnov, A. F., Golubiatnikov, G.Yu., Marlov V. N., and Sergeev, D. A., Pressure broadening of the rotational line of oxygen at $425 \mathrm{GHz}, 2002$ : J. Mol. Spectrosc. 215, 309-311.

Krupenie, P. H., 1972: The spectrum of molecular oxygen, J. Phys. Chem. Ref. Dat. 1, 423-534.

Kuhn, T., Bauer, A., Godon, M., Buehler. S., and Kunzi, K., 2002: Water vapor continuum: absorption measurements at $350 \mathrm{GHz}$ and model calculations, J. Quant. Spectrosc. Radiat. Transfer 74, 545562. 
Lacome, N., Levy, A., and Boulet, Ch., 1983: Air-broadened linewidths of nitrous oxide: an improved calculation, J. Mol. Spectrosc. 97, 139-153.

Lahoz, W. A., O’Neill, A., Carr, E. S., Harwood, R. S., Froidevaux, L., Read, W. G., Waters, J. W., Kumer, J. B., Mergenthaler, J. L., Roche, A. E., Peckham, G. E., and Swinbank, R., 1994: Three-dimensional evolution of water vapor distributions in the northern hemisphere stratosphere as observed by the MLS, J. of the Atm. Science 51, 29142930.

Lanquetin, R., Coudert, L. H., and Camy-Peyret, C., 1999: High-lying rotational levels of water: comparison of calculated and experimental energy levels for (000) and (010) up to $J=25$ and 21, J. Mol. Spectrosc. 195, 54-67.

Lanquetin, R., Coudert, L. H., and Camy-Peyret, C., 2001: High-lying rotational levels of water: an analysis of the energy levels of the five first vibrational states, J. Mol. Spectrosc. 196, 83-103.

Larsen, R. W., Nicolaisen, F. M., and Sørensen, G. O., 2001: Determination of self-air and oxygen broadening coefficients of pure rotational absorption lines of ozone and of their temperature dependencies, J. Mol Spectrosc. 210, 259-270.

Laurie, V. W., and Pence, D. T., 1962: Microwave spectrum structure and dipole moment of carbonyl fluoride, J. Chem. Phys. 37, 2995-2999.

Lemaire, V., Babay, A., Lemoine, C., Rohart, F., and Bouanich, J.-P., 1996: Self- and foreign-gasbroadening and shifting of lines in the $v_{2}$ band of HCN, J. Mol. Spectrosc. 177, 40-45.

Liebe, H. J., 1984: The atmospheric water vapor continuum below $300 \mathrm{GHz}$., International Journal of Infrared and Millimeter Waves 5, 207-227.

Liebe, H. J., 1985: An updated model for millimeter wave propagation in moist air, Radio Science 20, 1069-1089.

Liebe, H. J., 1989: MPM an atmospheric millimeter-wave propagation model, International Journal of Infrared and Millimeter Waves 10, 631-650.

Liebe, H. J., Rosenkranz, P. W., and Hufford, G. A., 1992: Atmospheric $60 \mathrm{GHz}$ oxygen spectrum: new laboratory measurements and line parameters, J. Quant. Spectrosc. Radiat. Transfer 48, 629643.

Livesey, N. J., Read, W. G., Froidevaux, L., Waters, J. W., Santee, M. L., Pumphrey, H. C., Wu, D. L., Shippony, Z., and Jarnot, R. F., 2003: The UARS Microwave Limb Sounder version 5 data set: Theory, characterization, and validation, J. Geophys. Res. D108, doi:10.1029/2002JD002273.

Lovas, F. J., 1978: Microwave spectral tables. II. Triatomic molecules, J. Phys. Chem. Ref. Data 7 , 1445-1750.

Lovas, F. J., 1985: Microwave spectra of molecules of astrophysical interest. XXII. Sulfur dioxide $\left(\mathrm{SO}_{2}\right)$, J. Phys. Chem. Ref. Data 14, 395-488.

Lovas, F. J., 2004: NIST recommended rest frequencies for observed interstellar molecular microwave Transitions-2002 revision, J. Phys. Chem. Ref. Data 33, 177-355.

Lyulin, O. M., Perevalov, V. I., and Teffo, J.-L., 1995: Effective dipole moment and band intensities of nitrous oxide, J. Mol. Spectrosc. 174, 566-580.

Ma, Q. and Tipping, R. H., 1990: Water vapor continuum in the millimeter spectral region, J. Chem. Phys. 93, 6127-6139.

Ma, Q. and Tipping, R. H., 1992: A far wing line shape theory and its applications to the foreign broadened water continuum absorption, J. Chem Phys. 97, 818-828.

Ma, Q. and Tipping, R. H., 2002: Water vapor millimeter wave foreign continuum: a Lanczos calculation in the coordinate representation, J. Chem. Phys. 117, 10581-10596.

Malathy Devi, V., Rinsland, C. P., Smith, M. A. H., Benner, D. Ch., and Fridovitch, B., 1986: Tunable diode laser measurements of air broadened linewidths in the $v_{6}$ band $\mathrm{H}_{2} \mathrm{O}_{2}$, Appl. Opt. 25, 1844-1847.

Markov, V. N. and Krupnov, A. F., 1995: Measurements of the pressure shift of the $1_{10}-1_{01}$ water line at $556 \mathrm{GHz}$ produced by mixtures of gases, J. Mol. Spectrosc. 172, 211-214. 
Matsushima, F., Odashima, H., Iwaskai, T., and Tsunekawa, S., 1995: Frequency measurement of pure rotational transitions of $\mathrm{H}_{2} \mathrm{O}$ from 0.5 to $5 \mathrm{THz}$, J. Mol. Struct. 352-353, 371-378.

May, R. D., 1992: Line intensities and collisional broadening for the $v_{4}$ and $v_{6}$ bands of $\mathrm{COF}_{2}$, J. Quant. Spectrosc. Radiat. Transfer 48, 701-712.

Meerts, W. L., De Leeuw, F. H., and Dymanus, A., 1977: Electric and magnetic properties of carbone monoxide by molecular beam electric resonance spectroscopy, Chem. Phys. 22, 319324.

Merino, F., Murtagh, D., Baron, P., Ricaud, P., de La Noë, J., and Eriksson, J. E. P., 2002: Studies for the Odin Sub-Millimeter Radiometer: III. Performance simulations, Can. J. Phys. 80, 357-373.

Messer, J. K. A., De Lucia, F. C., and Helminger, P., 1983: The pure rotational spectrum of water vapor-a millimeter, submillimeter, and far infrared analysis, Int. J. Infrar., and Mill. Waves $\mathbf{4}$, 505-539.

Messer, J. K. A., De Lucia, F. C., and Helminger, P., 1984: Submillimeter spectroscopy of the major isotopes of water, J. Mol. Spectrosc. 105, 139-155.

Mizushima, M. and Yamamoto, S., 1991: Microwave absorption lines of ${ }^{16} \mathrm{O}^{18} \mathrm{O}$ in its $\left(\mathrm{X}^{3} \Sigma_{g}^{-}, v=0\right)$ state, J. Mol. Spectrosc. 148, 447-452.

Morino, I., and Yamada, K. M. T., 2003: Absorption profiles of $\mathrm{N}_{2} \mathrm{O}$ measured for the $J=25-24$ and 26-25 rotational transitions, J. Mol. Spectrosc. 219, 282-289.

Muenter, J. S., 1975: Electric dipole of carbon monoxide, J. Mol. Spectrosc. 155, 490-491.

Murtagh, D., Frisk, U., Merino, F., Ridal, M., Jonsson, A., Stegman, J., Witt, G., Eriksson, P., Jimenez, C., Mégie, G., de La Noë, J., Ricaud, P., Baron, P., Pardo, J. R., Hauchecorne, A., Llewellyn, E. J., Degenstein, D. A., Gattinger, R. L., Lloyd, N. D., Evans, W. F. J., McDade, I. C., Haley, C. S., Sioris, C., von Savigny, C., Solheim, B. H., McConnell, J. C., Strong, K., Richardson, E. H., Leppelmeier, G. W., Kyrölä, E., Auvinen, H., and Oikarinen, L., 2002: An overview of the Odin atmospheric mission, Can. J. Phys. 80, 309-319.

Nadler, S., Daunt, S. J., and Reuter, D. C., 1987: Tunable diode laser measurements of formaldehyde foreign-gas broadening parameters and line strengths in the 9-11 $\mu \mathrm{m}$ region, Applied Opt. 26, 1641-1646.

Nedoluha, G., Bevilacqua, R., Gomez, R., Thacker, D., Waltmann, W., and Pauls, T., 1995: Groundbased measurements of water vapor in the middle atmosphere, J Geophys Res. D100, 2927-2939.

Nelson, D. D., and Zahniser, M. S., 1994: Air broadened linewidth measurements in the $v_{2}$ vibrational band of hydroperoxyl radical, J. Mol. Spectrosc. 166, 273-279.

Nerf, R. B., 1975a: Pressure broadening and shift (self-hydrogen- and helium-) in the millimeter wave spectrum of formaldehyde, J. Mol. Spectrosc. 58, 451-473.

Nerf, R. B., and Sonnenberg, M. A., 1975b: Pressure broadening of the $J=1-0$ transition of hydrogen cyanide, J. Mol Spectrosc. 58, 479-480.

Nolt, I. G., Radostitz, J. V., Dilonardo, G., Evenson, K. M., Jennings, D. A., and Leopold, K. R., 1987: Accurate rotational constants of $\mathrm{CO}, \mathrm{HCl}$ and HF: spectral standards for the $0-3$ to $6 \mathrm{THz}$ (10-200 $\mathrm{cm}^{-1}$ ) region, J. Mol. Spectrosc. 125, 490-491.

Odashima, H., Zink, L. R., and Evenson, K. M., 1999: Tunable far-infrared spectroscopy of HF, $\mathrm{H}^{35} \mathrm{Cl}$, and $\mathrm{H}^{37} \mathrm{Cl}$ in the 6 to $9 \mathrm{THz}$ region, J. Mol. Spectrosc. 194, 283-284.

Oh, J. J., and Cohen, E. A., 1994: Pressure broadening of $\mathrm{ClO}$ by $\mathrm{N}_{2}$ and $\mathrm{O}_{2}$ near 204 and $649 \mathrm{GHz}$ and new frequency measurements between 632 and $725 \mathrm{GHz}$, J. Quant. Spectrosc. Radiat. Transfer 52, 151-156.

Pardo, J. R., Pagani, L., Gerin, M., and Prigent, C., 1995: Evidence of the Zeeman splitting in the $2_{1}$ to $0_{1}$ rotational transition of the atmospheric ${ }^{16} \mathrm{O}^{18} \mathrm{O}$ molecule from ground-based measurements, J. Quant. Spectrosc. Radiat. Transfer 54, 931-943.

Pardo, J. R., Pagani, L., Olofsson, G., Febvre, P., Tauber, J., 2000: Balloon-borne submillimeter observations of upper stratospheric $\mathrm{O}_{2}$ and $\mathrm{O}_{3}$, J. Quant. Spectrosc. Radiat. Transfer 67, 169180. 
Pardo, J. R., Ridal, M., Murtagh, D., and Cernicharo, J., 2002: Microwave temperature and pressure measurements with the Odin satellite: I Observational method, Can. J. Phys. 80, 443-454.

Park, K., Chance, K. V., Nolt, I. G., Radostitz, J. V., Vanek, M. D., Jennings, D. A., and Evenson, K. M., 1991: Pressure broadening of the $2.5 \mathrm{THz} \mathrm{H}^{35} \mathrm{Cl}$ rotational line by $\mathrm{N}_{2}$ and $\mathrm{O}_{2}, \mathrm{~J} . \mathrm{Mol}$. Spectrosc. 147, 521-525.

Paulse, C. D., Coudert, L. H., Goyette, T. M., Crownover, R. L., Helminger, P., and De Lucia, F. C., 1996: Torsional splitting in the $v_{9}$ band of nitric acid, J. Mol. Spectrosc. 177, 9-18.

Pearson, J. C., Anderson, T., Herbst, E., De Lucia, F. C., and Helminger, P., 1991: Millimeter- and submillimeter-wave spectrum of highly excited states of water, Astr. J. Lett. L379, 41-43.

Perrin, A., Flaud, J.-M., Camy-Peyret, C., Carli, B., and Carlotti, M., 1988: The far infrared spectrum of $\mathrm{NO}_{2}$-Electron spin resonance and hyperfine Fermi contact resonance in the ground state, $\mathrm{Mol}$. Phys. 63, 791-810.

Perrin, A., Camy-Peyret, C., and Flaud, J.-M., 1992: Infrared Nitrogen Dioxide in the HITRAN database, J. Quant. Spectrosc. Radiat. Transfer 48, 645-652.

Perrin, A., Flaud, J.-M., Camy-Peyret, C., Schermaul, R., Winnewisser, M., Mandin, J.-Y., Dana, V., Badaoui, M., and Koput, J., 1996: Line intensities in the far infrared spectrum of $\mathrm{H}_{2} \mathrm{O}_{2}, \mathrm{~J} . \mathrm{Mol}$. Spectrosc. 176, 287-296.

Perrin, A., Flaud, J.-M., Goldman, A., Camy-Peyret, C., Lafferty, W. J., Arcas, Ph., and Rinsland, C. P., 1998a: $\mathrm{NO}_{2}$ and $\mathrm{SO}_{2}$ line parameters: 1996 HITRAN update and new results, J. Quant. Spectrosc. Radiat. Transfer 60, 839-850.

Perrin, A., 1998b: Recent progress in the analysis of $\mathrm{HNO}_{3}$ spectra, Spectrochimica Acta A54, 375393.

Perrin, A., Orphal, J., Flaud, J.-M., Klee, S., Mellau, G., Mäder, H., Walbrodt, D., and Winnewisser, M., 2004: New analysis of the $v_{5}$ and $2 v_{9}$ bands of $\mathrm{HNO}_{3}$ by infrared and millimeter wave techniques: line positions and intensities, J. Mol. Spectrosc. 228, 375-391.

Petkie, D. T., Goyette, T. M., Helminger, P., Pickett, H. M., and De Lucia, F. C., 2001: The energy levels of the $v_{5} / 2 v_{9}$ dyad of $\mathrm{HNO}_{3}$ from millimeter and submillimeter rotational spectroscopy, $J$. Mol. Spectrosc. 208, 121-135.

Petkie, D. T., Helminger, P., Butler, R. A. H., Albert, S., and De Lucia, F. C., 2003: The millimeter and submillimeter spectra of the ground and excited $v_{9}, v_{8}, v_{7}$, and $v_{6}$ vibrational states of $\mathrm{HNO}_{3}$, J. Mol. Spectrosc. 218, 127-130.

Pickett, H. M., Cohen, E. A., and Margolis, J. S., 1985: The infrared and microwave spectra of ozone for the $(0,0,0),(1,0,0)$, and $(0,0,1)$ states, J. Mol. Spectrosc. 110, 186-214.

Pickett, H. M., Cohen, E. A., Brown, L. R., Rinsland, C. P., Smith, M. A. H., Malathy Devi, V., Goldman, A., Barbe, A., Carli, B., and Carlotti, M., 1988: The vibrational and rotational spectra of ozone for the $(0,1,0)$ and $(0,2,0)$ states, J. Mol. Spectrosc. 128, 151-171.

Pickett, H. M., Poynter, R. L., Cohen, E. A., Delitsky, M. L., Pearson, J. C., and Müller, H. S. P., 1998: Submillimeter millimeter and microwave spectral line catalog, J. Quant. Spectrosc. Radiat. Transfer 60, 883-890.

Pine, A. S. and Fried, A., 1985: Self broadening in the fundamental bands of HF and HCl, J. Mol. Spectrosc. 114, 148-162.

Pine, A. S. and Looney, J. P., 1987: $\mathrm{N}_{2}$ and air broadening in the fundamental bands of $\mathrm{HF}$ and $\mathrm{HCl}$, J. Mol. Spectrosc. 122, 41-44.

Poynter, R. L., and Pickett, H. M., 1985: Submillimeter, millimeter and microwave spectral line catalog, Appl. Opt. 24, 2235-2240.

Pourcin, J., 1972: Fourier spectrometry of the broadening of the rotational spectra of $\mathrm{HCl}$ in the far infrared by helium, J. Quant. Spectrosc. Radiat. Transfer. 12, 1617-1625.

Pourcin, J. Jacquemoz, A., Fournel, A., and Sielmann, H., 1981: Pressure-broadening spectroscopy of $\mathrm{HCl}$ pure rotational lines with a far-infrared optically pumped laser, J. Mol. Spectrosc. 90, 4350 . 
Priem, D., Rohart, F., Colmont, J.-M., Wlodarczak, G., and Bouanich, J. P., 2000a: Lineshape study of the $J=3 \leftarrow 2$ rotational transition of $\mathrm{CO}$ perturbed by $\mathrm{N}_{2}$ and $\mathrm{O}_{2}, J$. Mol. Struct. 517-518, $435-454$

Priem, D., Colmont, J.-M., Rohart, F., Wlodarczak, G., and Gamache, R. R., 2000b: Relaxation and lineshape of the 500.4-GHz line of ozone perturbed by $\mathrm{N}_{2}$ and $\mathrm{O}_{2}$, J. Mol. Spectrosc. 204, 204-215.

Pumphrey, H. C., and S. Buhler, 2000: Instrumental and spectral parameters: their effect on and measurements by microwave limb sounding of the atmosphere, J. Quant. Spectrosc. Radiat. Transfer. 64, 421-437.

Puzzarini, C., Dore, L., and Cazzoli, G., 2002: A comparison of lineshape models in the analysis of modulated and natural rotational line profiles: application to the pressure broadening of OCS and CO, J. Mol. Spectrosc. 216, 428-436.

Raffalski, U., Klein, U., Franke, B., Langer, J., Sinnhuber, B.-M., Trentmann, J., Künzi, K.-F., Schrems, O., 1998: Ground based millimeter-wave observations of Arctic chlorine activation during winter and spring 1996/97, Geophys Res Lett. 25, 3331-3334.

Reinartz, J.-M.-L.-J., Meerts, W. L., and Dymanus, A., 1978: Hyperfine structure, electric and magnetic properties of ${ }^{14} \mathrm{~N}_{2}{ }^{16} \mathrm{O}$ in the ground and first excited bending vibrational state, Chem. Phys. 31, 19-29.

Ridal, M., Murtagh, D., Merino, F., Pardo, J. R., and Pagani, L., 2002: Microwave temperature and pressure measurements with the Odin satellite: II Retrieval method, Can. J. Phys., 80, 455467.

Rinsland, C. P., Goldman, A., Smith, M. A. H., and Malathy Devi, V., 1991a: Measurements of Lorentz air-broadening coefficients and relative intensities in the $\mathrm{H}_{2}{ }^{16} \mathrm{O}$ pure rotational and $v_{2}$ bands from long horizontal path atmospheric spectra, Appl. Opt. 30, 1427-1429.

Rinsland, C. P., Smith, M. A. H., Malathy Devi, V., and Benner, D. Ch., 1991b: Measurements of Lorentz broadening coefficients and pressure induced line shifts coefficients in the $v_{2}$ band of $\mathrm{D}_{2}{ }^{16} \mathrm{O}$, J. Mol. Spectrosc. 150, 173-183.

Rinsland, C. P., Goldman, A., and Flaud, J.-M., 1992: Infrared spectroscopic parameters of $\mathrm{COF}_{2}$, $\mathrm{SF}_{6}, \mathrm{ClO}, \mathrm{N}_{2}$ and $\mathrm{O}_{2}$, J. Quant. Spectrosc. Radiat. Transfer 48, 685-692.

Rodgers, C. D., 2000: Inverse Methods for Atmospheric Sounding: Theory and Practise, Series on Atmospheric, Oceanic and Planetary Physics, 2, World Scientific Publ., February (2000).

Rohart, F., Colmont, J.-M., Wlodarczak, G., and Bouanich, J. P., 2003: $\mathrm{N}_{2}$ - and $\mathrm{O}_{2}$-broadening coefficients and profiles for millimeter lines of ${ }^{14} \mathrm{~N}_{2} \mathrm{O}$, J. Mol. Spectrosc. 222, 159-171.

Rosenkranz, P. W., 1998, 1999: Water vapor microwave continuum absorption: A comparison of measurements and models, Radio Science 33, 919-928 (1998), (correction in 34, 1025, (1999)).

Rothman, L. S., Goldman, A., Gillis, J. R., Gamache, R. R., Pickett, H. M., Poynter, R. L., Husson, N., and Chedin, A., 1983: AFGL trace gas compilation, Appl. Opt. 22, 1616-1627.

Rothman, L. S., Gamache, R. R., Tipping, R. H., Rinsland, C. P., Smith, M. A. H., Benner, D., Malathy, Ch.,Devi, V., Flaud, J.-M., Camy-Peyret, C., Perrin, A., Goldman, A., Massie, S. T., Brown, L. R., and Toth, R. A., 1992: The HITRAN molecular database: editions of 1991 and 1992, J. Quant. Spectrosc. Radiat. Transfer 48, 469-507.

Rothman, L. S., Rinsland, C. P., Goldman, A., Massie, S. T., Edwards, D. P., Flaud, J.-M., Perrin, A., Dana, V., Mandin, J.-Y., Schroeder, J., McCann, A., Gamache, R. R., Wattson, R. B., Yoshimo, K., Chance, K., Jucks, K., Brown, L. R., Nemtchinov, V., and Varanasi, P., 1998: The HITRAN spectroscopic database and HAWKS (HITRAN Workstation): 1996 edition, J. Quant. Spectrosc. Radiat. Transfer 60, 665-710.

Rothman, L. S., Barbe, A., Benner, D. C., Brown, L. R., Camy-Peyret, C., Carleer, M. R., Chance, K., Clerbaux, C., Dana, V., Devi, V. M., Fayt, A., Flaud, J.-M., Gamache, R. R., Goldman, A., Jacquemart, D., Jucks, K. W., Lafferty, W. J., Mandin, J.-Y., Massie, S. T., Nemtchinov, V., Newnham, D. A., Perrin, A., Rinsland, C. P., Schroeder, J., Smith, K. M., Smith, M. A., Tang, K., Toth, R. A., Vander Auwera, J., Varanasi, P., and Yoshino, K., 2003: The HITRAN molecular 
spectroscopic database: edition of 2000 including updates through 2001, J. Quant. Spectrosc. Radiat. Transfer 82, 5-44.

Sandor, B. J. and Clancy, R. T., 1997: Mesospheric observations and modeling of the Zeeman split $233.9 \mathrm{GHz}{ }^{16} \mathrm{O}^{18} \mathrm{O}$ line, Geophys. Res. Lett. 24, 1631-1634.

Scharpen, L. H., Muenter, J. S., and Laurie, V. W., 1970: Electric polarizability anisotropies of nitrous oxide, propyne, and carbonyl sulfide by microwave spectroscopy, J. Chem. Phys. 53, 25132519.

Shorter, J. H., Nelson, D. D., and Zahniser, M. S., 1997: Air broadened linewidths in the $v_{2}$ band of HOCl, J. Chem. Soc., Faraday Trans. 93, 2933-2935.

Singbeil, H. E. G., Anderson, W. D., Davis, R. W., Gerry, M. C. L., Cohen, E. A., Pickett, H. M., Lovas, F. J., and Suenram, R. R., 1984: The microwave and millimeter wave spectra of hypochlorous acid, J. Mol. Spectrosc. 103, 466-485.

Steinbach, W. and Gordy, W., 1975: Microwave spectrum and molecular constants of ${ }^{16} \mathrm{O}^{18} \mathrm{O}$, Phys. Rev. A11, 729-731.

Teffo, J.-L., Perevalov, V. I., and Lyulin, O. M., 1994: Reduced effective Hamiltonian for a global treatment of rovibrational energy levels of nitrous oxide, J. Mol. Spectrosc. 168, 390-403.

Tejwani, G. D. T., 1972: Calculation of pressure-broadened linewidths of $\mathrm{SO}_{2}$ and $\mathrm{NO}_{2}$ ", J. Chem. Phys. 57, 4676-4682.

Tejwani, G. D. T., and Yeung, E. S., 1977: Pressure-broadened linewidths of formaldehyde, J. Chem. Phys. 66, 491-492.

Tejwani, G. D. T., and Yeung, E. S., 1978: Pressure broadened linewidths of $\mathrm{HNO}_{3}$, J. Chem Phys. 68, 2012-2013.

Tipping, R. H. and Ma, Q., 1995: Theory of water vapor continuum and validations, Atm. Res. 36, 69-94.

Titz, R., Birk, M., Hausamann, D., Nitsche, R., Schreier, F., Urban, J., Küllmann, H., and Röser, H., 1995: Observation of stratospheric $\mathrm{OH}$ at $2.5 \mathrm{THz}$ with an airborne heterodyne system, Infrared Phys Technol 36, 883-891.

Toth, R. A., 1993a: The $v_{1}-v_{2}, v_{3}-v_{2}, v_{1}$, and $v_{3}$ bands of $\mathrm{H}_{2}{ }^{16} \mathrm{O}$ : line positions and strengths, J. Opt. Soc. Am B 10, 2006-2029.

Toth, R. A., 1993b: The. $v_{2}-v_{2}$ and $2 v_{2}$ bands of $\mathrm{H}_{2}{ }^{16} \mathrm{O}, \mathrm{H}_{2}{ }^{17} \mathrm{O}$ and $\mathrm{H}_{2}{ }^{18} \mathrm{O}$ : line positions and strengths, J. Opt. Soc. Am B 10, 1526-1544.

Toth, R. A., 1993c: Line strengths $\left(900-3600 \mathrm{~cm}^{-1}\right)$, self broadened linewidths, and frequency shift (1800-2360 $\mathrm{cm}^{-1}$ ) of $\mathrm{N}_{2} \mathrm{O}$, Appl. Opt. 32, 7326-7365.

Toth, R. A.. 1998: Water vapor measurements between 590 and $2582 \mathrm{~cm}-1$ : Line positions and strengths, J. Mol. Spectrosc. 190, 379-396.

Tretyakov, M.Yu., Parshin, V. V., Koshelev, M. A., V. N.Shanin, Myasnikova, S. E., and Krupnov, A. F., 2003: Studies of the $183 \mathrm{GHz}$ line: broadening and shifting by air, $\mathrm{N}_{2}$ and $\mathrm{O}_{2}$ and integral intensity measurements, J. Mol. Spectrosc. 218, 239-245.

Tretyakov, M. Yu, Golubiatnikov, G. Yu, Parshin, V. V., Koshelev, M. A., Myasnikova, S. E., Krupnov, A. F., and Rosenkranz, P. W., 2004: Experimental study of the line mixing coefficient for 118.75 GHz oxygen line, J. Mol. Spectrosc. 223, 31-38.

Urban, J., Baron, Lautié, P., Schneider, N., Dassas, K., Ricaud, P., De La Noë, J., 2004: Moliere (v5): a versatile forward- and inversion model for the millimeter and sub-millimeter wavelength range, J. Quant. Spectrosc. Radiat. Transfer. 83, 529-554.

Verdes, C. L.,von Engen, A., Buehler, S. A., Perrin, A., 2004: Partition function data and impact on retrieval quality for an mm/sub-mm limb sounder, J. Quant. Spectrosc. Radiat. Transfer. 90, 217-238.

Verdes, C. L., Buehler, S. A., Perrin, A., Flaud, J.-M., Demaison, J., Wlodarczak, G., Colmont, J.-M., Cazzoli, G., and Puzzarini, C., 2005: A sensitive study on spectroscopic parameters accuracies for a mm/sub-mm limb sounder instrument, J. Mol. Spectrosc. 229, 266-275. 
Wagner, W., Birk, M., Schreier, F., and Flaud, J.-M., 2002: Spectroscopic data base of the three ozone fundamentals, J. Geophys. Res. D107, ACH10-1-10-18.

Watson, J. K. G., 1977: Aspects of quartic and sextic centrifugal effects on rotational energy levels, J.Durig ed., in Vibrational spectra and structure, 1-89, Elsevier, Amsterdam, Netherlands.

Winnewisser, G., Belov, S. P., Klauss, Th., and Schieder, R., 1997: Subdoppler measurements on the rotational transitions of carbon monoxide, J. Mol. Spectrosc. 184, 468-472.

Wlodarczak, G., Segard, B., Legrand, J., and Demaison, J., 1985a: The dipole moment of $\mathrm{CH}_{3}^{35} \mathrm{Cl}$, microwave and submillimeter wave spectrum of methyl chloride, J. Mol. Spectrosc. 111, 204-206.

Wlodarczak, G., Herlemont, F., Demaison, J., Fayt, A., and Lahaye, J. G., 1985b: Combined subdoppler laser-Stark and millimeter wave spectroscopies, J. Mol. Spectrosc. 112, 401-412.

Wlodarczak, G., Boucher, D., Bocquet, R., and Demaison, J., 1986: The microwave and submillimeter wave spectrum of methyl chloride, J. Mol. Spectrosc. 116, 251-255.

Yaron, D., Peterson, K., and Klemperer, W., 1988: On the dipole moment functions of $\mathrm{ClO}$ and $\mathrm{OH}$, J. Chem. Phys. 88, 4702-4710.

Yamada, M. M., Koboyashi, M., Habara, H., Amano, T., and Drouin, B. J., 2003: Submillimeterwave measurements of the pressure broadening of BrO, J. Quant. Spectrosc. Radiat. Transfer $\mathbf{8 2}$, 391-399.

Zink, L. R., and Mizushima, M., 1987: Pure rotational far-infrared transitions of ${ }^{16} \mathrm{O}_{2}$ in its electronic and vibrational ground state, J. Mol. Spectrosc. 125, 154-158.

$\mathrm{Zu}$, L., Hamilton, P. A., and Davies, P. B., 2002: Pressure broadening and frequency measurements of nitric acid lines in the $683 \mathrm{GHz}$ region, J. Quant. Spectrosc. Radiat. Transfer. 73, 545-556. 